Research Square

\title{
Genetic Diversity, Population Structure and Relationship of Ethiopian Barley (Hordeum vulgare L.) Landraces as reveled by Simple Sequence Repeat (SSR) Markers
}

\author{
Allo Aman Dido \\ Ethiopian Biotechnology Institute \\ B.J.K. Singh \\ Koneru Lakshmaiah Education Foundation \\ Ermias Assefa \\ Ethiopian Biotechnology Institute \\ M.S.R. Krishna \\ Koneru Lakshmaiah Education Foundation \\ Dawit Degefu \\ Ethiopian Institute of Agricultural Research \\ Kassahun Tesfaye ( $\sim$ kassahun.tesfaye@aau.edu.et) \\ Ethiopian Biotechnology Institute
}

\section{Research Article}

Keywords: Genetic diversity, Hordeum vulgare, Landraces, population structure, Simple sequence repeat

Posted Date: February 22nd, 2021

DOI: https://doi.org/10.21203/rs.3.rs-228186/v1

License: (c) (i) This work is licensed under a Creative Commons Attribution 4.0 International License. Read Full License 


\section{Abstract}

Characterization of genetic resources maintained at genebanks has important implications for future utilization and collection activities. A total of 49 simple sequence repeat (SSR) or microsatellite markers were used to study genetic diversity and relationships among 376 barley landraces collected from different barley producing parts of Ethiopia and eight cultivars. Overall, 478 alleles with an average of 9.755 alleles per locus were obtained of which $97.07 \%$ of the loci were observed to be polymorphic. Nei's genetic diversity index (h) was 0.654 , and the Shannon diversity index (I) was 0.647 , indicating that the genetic diversity in barley genotypes studies was moderately high. At the population level, the percentage of polymorphic loci (PPL) averaged $98.37 \%, \mathrm{~h}=$ averaged 0.388 , and $\mathrm{I}=$ averaged 0.568 . The highest level of genetic diversity was observed in the AR population $(\mathrm{PPL}=100 \%, \mathrm{~h}=0.439, \mathrm{I}=$ 0.624); the lowest was observed in the $\mathrm{JM}$ population ( $\mathrm{PPL}=75.51 \%, \mathrm{~h}=0.291, \mathrm{I}=0.430$ ). AMOVA revealed significant genetic differentiation within and between populations $(\mathrm{P}<0.001)$, with $84.21 \%$ of the variation occurring within populations and $15.79 \%$ occurring among populations. Genetic variation analysis showed a coefficient of gene differentiation of 0.053 and a gene flow value of 4.467 among populations. The 384 barley genotypes were divided into seven genetic clusters according to STRUCTURE, Neighbour joining tree and principal coordinate analysis, correlating significantly with geographic distribution. These results will assist with the formulation of conservation strategies, such as genetic rescue and on-farm in situ and ex situ conservation.

\section{Introduction}

Barley (Hordeum vulgare L.) is one of the earliest domesticated annual cereal food crops and it is belongs to the grass family Poaceae, which contains 32 species and 45 taxa, including diploid $(2 n=2 x=14)$, tetraploid $(2 n=4 x=28)$, and hexaploid $(2 n=6 x=42)$ cytotypes with a basic chromosome number $x$ = 7 (von Bothmer and Jacobsen 1980; von Bothmer et al. 1982; von Bothmer et al. 1986; Amanda 2008). The crop is cultivated successfully in a wide range of environmental conditions and requires low production inputs (Alam et al. 2007). In Ethiopia, it is produced mainly as a food crop and is the fifth most important cereal crop after tef, maize, sorghum and wheat (Abebe et al. 2010). A long history of barley cultivation, coupled with complex topography and agro-ecological diversity, cultural diversity and artificial selection by early farmer in the country, has resulted in a large number of landraces of the crop which can adapt to different environmental conditions (Hadado et al. 2009).

The collection, evaluation, conservation and utilization of crop germplasm have become one of the top agricultural research priorities in Ethiopia (Lakew et al. 1997). Interest in the genetic diversity and structure of natural populations has increased because of the need to broaden knowledge of genetic variation in cultivated species (Che et al. 2008). A detailed understanding of genetic relationships among germplasm resources is vital for future crop breeding process to enhance yield, quality and resistance to both biotic and abiotic stresses (Wang et al. 2006). Furthermore, a thorough research on germplasm conserved in Genebank facilitates the introduction of useful traits into the existing commercial crop genetic bases (Tara Satyavathi et al. 2006).

Crop genetic diversity and relationship can be evaluated based on the differences in morphological traits, isozymes, DNA markers, as well as pedigree information and geographic origins. As compared with restriction fragment length polymorphism (RFLP), amplified fragment length polymorphism (AFLP) and random amplification of polymorphic DNA (RAPD) markers, simple sequence repeats (SSR) have been shown to produce higher levels of polymorphisms with much greater ability to identify unique alleles in the crop germplasm (Barkley et al. 2007). SSR markers are also known as microsatellite and constitute a superior molecular marker system, offering the advantages of being codominant, abundant, highly reproducible, highly polymorphic and easy to assay. They can also be found anywhere in the genome, in both coding and non-coding region (Varshney et al. 2005) and they are usually characterized by a high degree of length polymorphism (Zane et al. 2002). SSRs have been used to study genetic diversity in various crop species, including maize (Eleuch et al. 2008), soybean (Wen et al. 2009), sorghum (Li et al. 2010), cowpea (Badiane et al. 2012) and foxtail millet (Wang et al. 2012). SSRs have also been used to construct linkage maps, assess phylogenetic and population genetic relationships and identify molecular markers for marker-assisted selection in wheat (Song et al. 2005), barley crosses (Hearnden et al. 2007), groundnut (Varshney et al. 2009), peanut (Hong et al. 2010), Bermuda grass (Guo et al. 2011) and Walnut (Kefayati et al. 2019).

Several studies on the analysis of genetic diversity and population structure in local and worldwide barley landraces have been conducted using SSR markers (Chen et al. 2012; Bellucci et al. 2013; Pasam et al. 2014). In Ethiopia, genetic diversity studies performed in different germplasm collections using morphological, biochemical and molecular markers (Bekele 1983; Asfaw 1989; Demissie and Bjornstad 1997; Abebe et al. 2010), However, most of these studies were based on either collections from distinct geographical regions only or very few samples collected from wider geographical ranges or few samples and cropping seasons or mixtures of landraces and cultivars. In the present study, we carried out genetic diversity and population structure of diverse barley collections adapted to wide range of climates ( from 42 agro-ecological zones with altitude ranges from $1030 \mathrm{~m}$ above sea level to $2950 \mathrm{~m}$ ) by using simple sequence repeat(microsatellite) markers.

\section{Materials And Methods}

\section{Plant Material}

A total of 384 barley genotypes, including 376 landraces and 8 cultivars were used in this study. The commercial cultivars used in this analysis include Abdanie, Guta, Dafo, HB-1964, HB-1966, HB-42, Ardu-12-60B and Aruso (six-rowed barley). These improved commercial varieties were obtained from Holetta and Sinana Agricultural Research Centers in the central and southeastern highlands of Ethiopia, respectively. On the other hand, the landraces were obtained from the Ethiopian Biodiversity Institute (EBI) along with their passport data. For data analysis, the improved varieties were only used to study the relationship within and among barley genotypes. Landraces from regions with sample size less than five were also included in adjacent regions to reduce experimental error due to small sample size. This reduced the 42 agro-ecological zones from which the landraces were originally drawn to 15 
zones viz. Oromia (six zones), Amhara (three zones), Tigray (two zones), Southern Nations, Nationalities and Peoples, SNNP (three zones) and Benishangul Gumuz (one zone) (S1 Table).

The 384 collected barley landraces comprised 88 landraces collected from Amhara, 188 from Oromia, 42 from SNNP, 57 from Tigray and 9 from Benishangul Gumuz. Major barley growing highland regions of Ethiopia, the Oromia and Amhara regions, have been represented by more samples. The representative samples were carefully selected among Hordeum accessions available at Ethiopian Biodiversity Institute (EBI) ex-situ Genebank and those representing different geographical locations of the country together with their passport data. All landraces are of spring growth type of which 178 are two-rowed, 186 are six-rowed and 20 are irregular barley type (Table S1).

The original collection sites of the barley landraces are given in Figure 1 constructed using the software QGIS-ver. 3.8.0 using the GPS coordinates of the collection sites (S1 Table). All sets of the barley accessions (landraces and cultivars) used in this study, hereafter called genotypes, were regarded as a population and each grouping, based on geographic zones, kernel row number and improvement status (landraces and improved cultivars), were regarded as a subpopulation.

\section{Genomic DNA extraction}

A total of 10 seeds per accession were randomly selected and sown in plastic trays and allowed to grow in lath house compartment at Ethiopian Biotechnology Institute (EBTi) in 2019. Two weeks later, leaves from 10 randomly chosen plants per accession were collected, bulked together and stored at $-80^{\circ} \mathrm{C}$ until DNA isolation. Later approximately $100 \mathrm{mg}$ leave tissues of each genotype were placed in a $50 \mathrm{~mL}$ tube filled with silica gel in preparation for DNA extraction. Leaf tissue was powdered using Mixer Mill (Retsch $\mathrm{GmbH}$, Germany) at 25 times s $^{-1}$ for 5 min. Total genomic DNA was extracted from each fresh and dried leaf following modified CTAB protocol (Orabi et al. 2014). The presence and absence of gDNA was checked in agarose gel electrophoresis ( $0.8 \%$ Agarose in $100 \mathrm{ml}$ of $1 \mathrm{XTAE}, 5 \mu \mathrm{L}$ of gDNA+1.5 $\mu \mathrm{L}$ of $1 \mathrm{X}$ Loading dye) run for 30 min at $100 \mathrm{~V}$. Moreover, DNA quality and concentration was estimated using Nano Drop Spectrophotometer (ND-8000, Thermo-scientific). DNA samples were then diluted to a concentration of 20 $\mathrm{ng} / \mu \mathrm{L}$ using $\mathrm{ddH}_{2} \mathrm{O}$ and stored at $-20^{\circ} \mathrm{C}$ for SSR fingerprinting.

\section{Microsatellite primers}

Literature based search was done to find appropriate SSR markers for barley (S1 Table). Accordingly, in order to have a good coverage of the barley genome, forty nine primer pairs, seven from each chromosome, were selected from the published genetic maps (Varshney et al. 2007; Wang et al. 2010). All accessions were genotyped using 49 SSR (microsatellite) markers distributed over the entire barley genome for better coverage.

\section{PCR optimization, primer screening and PAGE}

Polymerase chain reaction (PCR) was optimized starting from the reaction set up described in Wang et al., (2010). Accordingly, PCR was carried out in a $25-\mu \mathrm{L}$ final volume containing $2 \mu \mathrm{L}$ of $20 \mathrm{ng} / \mu \mathrm{L}$ genomic DNA templates, $2.5 \mu \mathrm{L}$ of $1 \mathrm{X}$ PCR buffer containing $15 \mathrm{mM} \mathrm{Mg} 2+, 0.5 \mu \mathrm{L}$ of $15 \mathrm{mM}$ dNTP mixture (2.5 mM of each), $1.25 \mu \mathrm{L}$ of $5 \mathrm{u} / \mu \mathrm{L}$ of Taq DNA polymerase, and $0.25 \mu \mathrm{L}$ of $10 \mu \mathrm{M}$ forward and reverse primers and $18.5 \mathrm{ddH} \mathrm{H}_{2} \mathrm{O}$ for amplification. Reactions were carried out in a PTC-100 Thermo-Cycler (ALT INC., East Lyme, CT, USA) using the program as follows: (1) Initial denaturation at $94{ }^{\circ} \mathrm{C}$ for 5 min for one cycle, (2) 35 cycles of denaturation at $94^{\circ} \mathrm{C}$ for 30 seconds, (3) Annealing at temperature specific for each primer for 30 seconds, (4) extension at $72^{\circ} \mathrm{C}$ for 30 seconds and (5) a final extension at $72^{\circ} \mathrm{C}$ for 10 min with final holding at $4^{\circ} \mathrm{C}$. The success of the PCR and the associated yield was assessed on $2 \%$ agarose gel $(2 \mathrm{~g}$ agarose in $50 \mathrm{ml}$ of $1 \mathrm{xTAE}, 5 \mu \mathrm{L}$ of gDNA+1.5 $\mu \mathrm{L}$ of $1 \mathrm{X}$ Loading dye with gel red (mix (1000:1)) and run for $30 \mathrm{~min}$ at $100 \mathrm{~V}$. Once the optimization was over, the same PCR setup (as described above) was applied for amplification of SSRs with all the 49 primers across the entire barley samples genotyped.

\section{Scoring bands and data analysis}

Scoring bands following resolution by electrophoresis, the individual amplicon (SSR fragments) were scored manually in a binary format into a data matrix file, with the presence of a band scored as " 1 " and its absence scored as " 0 ".

\section{Genetic diversity analysis}

Allele presence and absence was scored for each SSR marker as 1 and 0, respectively. These scores were stored in an Excel file as a binary matrix and served as the basis of the genetic diversity analysis using GeneAlEx $6.51 \mathrm{~b} 2$ software (Peakall and Smouse, 2006), including: number of observed alleles $(\mathrm{Na})$, number of effective alleles $(\mathrm{Ne})$, percentage polymorphic loci (\%P), Shannon diversity index (I), Nei's genetic diversity ( $h$ ), expected heterozygosity $(\mathrm{He})$, observed heterozygosity $\left(\mathrm{H}_{\mathrm{o}}\right)$ and pairwise values of Nei's genetic distance (NGD) and genetic identity (NGI) among populations. Furthermore, 
polymorphic information content (PIC), major allele frequency (MAF), inbreeding coefficient $\left(F_{I S}\right)$ were calculated with the R packages diveRsity using the divBasic function (Keenan et al. 2013). Analysis of molecular variance (AMOVA) was carried out to partition the genetic variances into two levels: Among populations and within populations and conducted using the R package poppr (Kamvar et al. 2014). Pairwise $F_{S T}$ values between populations and gene flow based on SSR were calculated with GENEPOP version 4.2.1 (Rousset, 2008)

A cluster analysis among populations, based on UPGMA, was also developed using the PowerMarker v3.25 software (Liu and Muse, 2005). An unrooted tree was constructed based on pairwise standard genetic distances (Liu and Muse, 2005), using the least squares algorithm with 10,000 bootstrap replicates, and these processes were generated and analyzed using Molecular Evolutionary Genetic Analysis (MEGA) version 10.2.2 and Fig Tree Version 1.4.4 softwares.

\section{Population structure analysis}

To infer the population structure of Ethiopian barley landraces, three complementary methods were used: 1) Bayesian model-based clustering algorism (STRUCTURE software) (Pritchard et al., 2000), 2) discriminant analysis of principal components (DAPC) and 3) principal coordinate analysis (PCoA).

The structure analysis was run three times for each $\mathrm{K}$ value ( $\mathrm{K}=1$ to 15 ) using a burnin period of 50,000 with 100,000 Markov Chain Monte Carlo (MCMC) iterations, assuming an admixture model and uncorrelated allele frequencies. The most probable value of $\mathrm{K}$ for each test was detected by $\Delta \mathrm{K}$ (Evanno et al., 2005), using the web-based program Structure Harvester (Earl and vonHoldt, 2012). CLUMPP v.1.1.2 (Jakobsson and Rosenberg, 2007) was used to align cluster assignment from independent runs using the in-files generated by structure Harvest. Bar plots were generated with average results of runs for the most probable K value, using DISTRUCT v.1.1 (Rosenberg, 2004). As suggested in Ketema et al. (2020) genotype was considered to belong to a group if its membership coefficient was $\geq 0.70$. Genotypes with membership coefficient less than 0.70 at each assigned $\mathrm{K}$ were regarded as admixed.

To cross-check the results from the model-based population structure from STRUCTURE with a model-free other method, DAPC was used. DAPC is a multivariate method designed to identify and describe clusters of genetically related individuals and the analysis was performed using adegenet version 2.0.1 (Jombart et al. 2010) in the R environment. In the absence of a known grouping pattern, DAPC uses sequential K-means and model selection to build genetic clusters based on information from genetic data. The Bayesian information criterion (BIC) was used to identify an optimal number of genetic clusters $(K)$ to describe the data. Based on the calculation of the a-score, the optimal number of principal components was retained.

The number of clusters obtained from STRUCTURE and DAPC was compared with those from PCoA without any assumption about the underlying population genetic model and it was performed using GeneAlEx 6.51b2 (Peakall and Smouse, 2012). PCoA is a distance-based approach to dissect and display dissimilarities between individuals.

\section{Results}

Characterization and understanding of the genetic diversity and population structure of any species is very much essential to design any conservation strategy or genetic improvement program. In this study, a total of 49 SSR primers (S1 Table) that showed reproducible polymorphic amplification during screening step were used to analyze 384 individual genotypes of $H$. vulgare from Ethiopia covering 15 populations, resulted in a total of 478 alleles. The number of bands amplified ranged from 14 to 43 with an average of 31.533 bands per population. The SSR fragment size ranged from $114 \mathrm{bp}$ for HVM44 to $263 \mathrm{bp}$ for Bmac0040 SSR loci. The band pattern across these 15 populations is given in S1 Figure.

\section{SSR locus diversity and Polymorphic Information Index}

The parameters of the variability of the investigated loci are shown in Table 1. Overall, 478 alleles were observed at the 49 SSR loci with an average of 9.755 alleles per SSR marker. The major allele frequency varied from 0.531 (GMS116A) to 0.784 (EBmac0518) with average value of 0.689 . The number of allele per locus ranged from 5 (Bmac0316) to 18 (WMC1E8 and Bmac0040). The number of effective alleles (Ne) ranged between 1.047 (GMS116A) and 3.712 (HVLTPPB), with an overall mean of 2.068. The polymorphic information content (PIC) ranged from 0.243 (WMC1E8) to 0.885 (Bmac0040). Significant and positive correlations were found between PIC and He ( $r=0.91, P<0.001)$ PIC and number of alleles $(r=0.89$, P<0.001) and, He and number of alleles $(r=0.84, P<0.001)$.

Out of the total number of alleles 19.25\% were private alleles (92), with Bmag0337 scored maximum value of six and ten SSR markers (Bmac0316, Bmag0812, HVKNOX3, Bmac0093, WMS6, Bmag0135, HVM36, HvXan, Bmag0905 and Bmac0129b) revealed the null (0) sum of private alleles. The within-population insufficiency in heterozygosity (as determined by $\mathrm{F}_{\mathrm{IS}}$ factor), varied from -1.000 (Bmac0173, Bmac0273e, Bmac0093 and Bmag0905) to 0.742 (HvID) with a mean of 0.037 for all loci.

The inbreeding coefficient among populations $\left(\mathrm{F}_{\mathrm{IT}}\right)$ values ranged from -1.000 (Bmag0173, Bmac0273e, Bmac0093 and Bmag0905) to 0.625 (HVLTPPB), with a mean of 0.074 . The population differentiation (evaluated by $\mathrm{F}_{\mathrm{ST}}$ ) was estimated at 0.049 . The contribution of $49 \mathrm{SSR}$ for population segregation (determined by $\mathrm{F}_{\mathrm{ST}}$ statistics) varied from 0.000 (Bmag0173, Bmac0273e, Bmac0093 and Bmag0905) to 0.187 (WMC1E8). The overall F-statistics differed significantly $(\mathrm{p}<0.05)$ from zero. This differentiation had a significant contribution from all loci. The values for $\mathrm{H}_{\mathrm{O}}$ ranged from $0.112(\mathrm{HVM} 20)$ to 
0.420 (HVLTPPB), with an overall mean of 0.317, while the values of $H_{e}$ ranged from 0.260 (Bmac0129b) to 0.640 (GMS116A), with a general mean value of 0.479 . The average number of migrants per generation $(\mathrm{Nm})$ in the whole population ranged from 0.000 (Bmac0273e, $\mathrm{Bmag} 0173, \mathrm{Bmac0093}$ and Bmag0905) to 18.981 (Bmac0067) and across all the loci was found to be 6.613 . Only $12.25 \%$ of the loci in all barley populations, did not differ considerably $(p>0.05)$ from the HWE.

Other descriptive statistics were found to vary among loci and among genotypes studied. Among the analyzed SSR markers, a total of 92 alleles were found to be unique (i. e. occurred either in two-rowed, six-rowed or cultivars) as shown in Table 2. The two-rowed barley landraces possessed 43 (46.74\%) and the six-rowed barley type possessed 32 (34.78\%) unique alleles on the other hand, cultivars possessed 17 (18.48\%) unique (private) alleles.

\section{Genetic diversity indices for barley genotypes}

Genetic diversity indices for barley landraces based on origin (Administrative Zones), improvement status and kernel row number, is summarized in Table 3. All the loci were polymorphic. The observed and expected frequencies of heterozygote were not statistically different ( $p>0.05)$, hence, the inbreeding coefficient (F) estimates observed were not substantially different from zero. The mean number of alleles varied from 1.255 to 10.670 . The highest count of alleles (10.670) was found in the AR population. The highest count of private alleles (12) was observed in the WL population, while the GG, HD, and MT populations contained lower private alleles (2). The number of effective alleles ranged from 1.502 to 1.783 . The Shannon Index (I), which is an expression of population diversity in a particular habitat, was high in the AR (0.624) and low in JM population (0.430). Furthermore, the lowest observed heterozygosity was in the WL (0.368) while the highest was recorded in AR population (0.699). The expected heterozygosity in the populations ranged from 0.212 (for WG) to 0.503 (for GN population).

Similarly, all the loci were polymorphic for breeding status and kernel row types, and number of alleles varied from 7.380 to 9.345 (improvement status) and 3.405 to 6.751 (kernel row types). The numbers of private (unique) alleles were higher for landraces and for six-rowed barley types (Table 3).

\section{Population Structure and Clustering Analysis}

The two complementary methods (STRUCTURE and DAPC) used in determining the number of clusters among the sub-set of the barley collections. Both showed the presence of seven major clusters along with sub-clusters. The population structure of the 384 barley genotypes was inferred using STRUCTURE 2.3.4 and the peak of $\triangle \mathrm{K}$ was observed at $\mathrm{K}=7$ (Fig. 2A), suggesting the presence of seven main populations (7 clusters, C-I, C-II, C-III, C-IV, C$\mathrm{V}, \mathrm{C}-\mathrm{VI}$ and $\mathrm{C}-\mathrm{VII})$ in the barley genotypes studied across major barley growing regions of Ethiopia. The distribution of the tested barley genotypes based on DAPC plot (Fig. 2B), UPGMA clustering dendrogram (Fig. 3) and the model-based structure analysis (Fig. 4B) show that the accessions are divided into seven major clusters. Using 0.70 as the likelihood to cluster for each accession in the seven populations, a total of 336 genotypes (87.5\%) were grouped to one of the seven populations. In the first cluster, 46 (11.98\%) of total genotypes was grouped, in the third cluster, 63 (16.41\%), in seventh cluster, 56 (14.58\%) were grouped. The admixture comprised 48 genotypes (12.5\%) of total genotypes (Table 4). The proportions of membership of each predefined population in each of the clusters obtained at the best $\mathrm{K}(\mathrm{K}=7)$ from STRUCTURE and discriminant analysis of principal component (DAPC) is presented in Table 4. Unweighted pair group method with arithmetic mean (UPGMA) analysis from PowerMarker V3.25 and visualized with MEGA-X and Fig Tree also clearly divided the 384 genotypes into seven groups (Fig 3), which was consistent with the model-based population structure from STRUCTURE. Membership clustering using DAPC also grouped the genotypes into seven clusters (Fig 2B and Table 4).

The classification of accessions into populations based on the model-based structure from STRUCTURE 2.3.4 is shown in Fig 4 . To confirm the true value of $\mathrm{K}$, another model-free method, DAPC, was used. The optimum number of clusters was obtained with $\mathrm{K}=7$ using the Bayesian information criterion (BIC), which again divided the genotypes into seven sub-populations.

The pairwise genetic differentiation coefficient $\left(F_{S T}\right)$ between pairs of population was highly significant $(P<0.001)$, ranging from $0.012(T C$ and $T N$ and TC and WL) to 0.612 (TN and HD and GJ and GG) with a mean value of 0.210 (Table 5). Among the 15 populations, both TC and TN populations showed a relatively high differentiation from the other populations ( $50 \%$ of pairwise $\mathrm{F}_{\mathrm{ST}}>0.4$ ). Conversely, the estimated values for gene flow ( $\mathrm{Nm}$ ) between populations varied from 0.158 (between GG and GJ and TN and HD) to 20.583 (between TC and TN) with a mean value of 3.440 (Table 5).

\section{AMOVA and genetic partitioning}

The matrix of pairwise genetic distances between populations (Table 6 and Fig 5) showed low genetic distance (0.017) between AR and BL, populations. A similar trend was observed in GJ and GN (0.020) and TC and TN (0.018). On the other hand, the highest genetic distance (0.549) was observed between population from Sidama and two Tigray zones.

Analysis of molecular variance (AMOVA) based on geographical origin (Administrative Zones), breeding status (i.e., improved and local) and kernel row number (two-rowed, six-rowed and irregular) showed that the genetic variations within population (84.0\%, $90.0 \%$ and $98.0 \%)$ were larger than that among populations, based on zones of origin, breeding status and kernel row number ( $16 . \%, 10 \%$ and $2 \%$ ), respectively (Table 7 ). All of these variance components were highly significant, indicating that genetic differentiation within populations was significant.

Page 5/23 
The fixation index $\left(\mathrm{F}_{\mathrm{ST}}\right)$ values in a range of 0.0 to 0.05 generally considered as little differentiation, in the range of 0.05 to 0.15 suggested moderate differentiation, 0.15 to 0.25 large differentiation, and above 0.25 as very large differentiation. In this study, the observed $\mathrm{F}_{\mathrm{ST}}$ values based on Zones of genotypes origin, breeding status and kernel row number were $0.053,0.097$ and 0.221 , respectively, suggesting the presence of moderate differentiation. We also found that gene flow between regions was high as indicated by an $\mathrm{Nm}=4.467$ (Table 7).

Analysis of genetic differentiation were computed among 7 clusters based on DAPC analysis using the AMOVA method. Results indicated that 19.301\% and $80.699 \%$ of variations could be attributed to differentiation among clusters and within inferred clusters, respectively (S3 Table). $F_{\text {ST }}$ and gene flow $(\mathrm{Nm})$ among the studied population were $0.041(p<0.001)$ and 5.848 , respectively. Furthermore, pairwise cluster $\mathrm{F}_{\mathrm{ST}}$ was computed and estimated values for 7 clusters ranged from 0.057 (C2 with C7) to 0.204 (C3 with C4) (S4 Table). Also, pairwise cluster estimates of gene flow (Nm) for 7 clusters ranged from 0.978 (C3 with C4) to 4.595 (C1 with C5) migrants per clusters.

\section{Discussion}

\section{SSR marker polymorphism and its use in barley diversity assessment}

The SSR microsatellites are useful tools for identifying genetic relationships among varieties that are difficult to distinguish morphologically. It has also been used successfully to determine genetic diversity among many plants including barley (Varshney et al., 2004; Abebe et al., 2010; Shiferaw et al., 2012; Bellucci et al., 2013; Ren et al., 2014; El-Esawi, 2016; Chen et al., 2020).

In barley, the first molecular genetic maps comprised RFLP markers (Graner et al., 1991; Kleinhofs et al., 1993), however, through time, PCR based molecular markers became the dominant marker type (Varshney et al., 2004). Among different types of molecular markers available for barley, SSRs have been proven to be the markers of choice for marker-assisted selection (MAS) in breeding and genetic diversity studies, based on the identification of molecular patterns such as expected and observed heterozygosity and polymorphic information content (Varshney et al., 2005; Varshney et al., 2007). This is largely because they require small amounts of sample DNA, are easy to detect by PCR, are amenable to high-throughput analysis, co-dominantly inherited, multi-allelic, highly informative and abundant in genomes (Powell et al., 1996; Gupta and Varshney, 2000). The value of microsatellite markers for both genetic diversity studies and for barley breeding was demonstrated as early as 1994 (Saghai Maroof et al., 1994; Becker and Heun, 1995; Struss and Plieske, 1998). Later, comprehensive microsatellite genetic maps integrating SSR loci were prepared by Ramsay et al., (2000) and Li et al. (2003).

The SSR markers selected in this study yielded reproducible polymorphic bands in $384 \mathrm{H}$. vulgare L. genotypes and showed that they provide a powerful and reliable molecular tool for analyzing genetic diversity and relationships among $H$. vulgare genotypes. Overall, $97.07 \%$ of the bands generated by the SSR assay in this study were polymorphic, which was lower than the polymorphic proportions of $99.50 \%$ detected by SSR markers among barley accessions from Ethiopia as reported by Abebe et al. (2010). This variation could be explained by the type of SSR primers, sample type and size used in the studies.

Molecular marker with higher polymorphic information content (PIC) values is considered as powerful marker to identify and discriminate cultivars. A locus with an estimated PIC value greater than 0.50 is considered to be highly diverse (Botstein et al., 1980). In this study, the PIC values of the SSR markers used in the $H$. vulgare genotyping ranged between 0.243 and 0.885 , with an average of 0.727 . Among 49 primers used in this study, a total of 32 (65.3\%) primers have PIC value more than the average 0.727 which indicated that the highly informative SSR markers that could be employed in genetic diversity studies of $H$. vulgare L. genotypes.

\section{Levels of Genetic diversity among barley populations}

Molecular methods have become an essential part of most studies on genetic diversity extent and the studies may use RFLPs, RAPDs, AFLPs or SSRs. It is important, however, to understand that different markers have different properties and will reflect different aspects of genetic diversity (Karp and Edwards, 1995). In this study, the levels of genetic diversity of barley genotypes from various parts of Ethiopia were studied using SSR markers.

The average number of alleles, which is 9.76 per locus, for the 49 SSR loci was higher than values reported in other studies on barley (Abebe et al., 2010; Ould Med Mahmouda and Hamzaa, 2009); which could be associated with a higher number of landraces and primers used in this study. However, this is also a reflection of the diversity in Ethiopia, both arising from the fact that this is one of the, if not the major, centre of diversity of barley, and the fact that there are diverse end-uses for barley in this region. Moreover, Molina-Cano et al., (2005) and Orabi et al., 2007 based on chloroplast DNA were suggested that Horn of Africa, Ethiopia and Eritrea to be a possible center of origin and domestication for cultivated barely.

Among the analyzed SSR markers, a total of 92 alleles were found to be unique to two-rowed, six-rowed or cultivars (i. e. occurred either in two-rowed, sixrowed or cultivars). The two-rowed barley landraces possessed $46.74 \%$ and the six-rowed barley type possessed $34.78 \%$ unique alleles on the other hand, cultivars possessed $18.48 \%$ private alleles. Matus and Hayes (2002) suggested that the occurrence of so many unique alleles could be an indication of the relatively high rate of mutation (and diversity) at SSR loci and its potential as a reservoir of novel alleles required for plant breeding. The genetic diversity values for the SSR markers were high for all landraces as well as for landraces in each Zone, improvement status (particularly for those considered as landraces) and the kernel row numbers. 
The high diversity observed in Ethiopian barley landraces could be attributed to various factors including evolution of cultivated barley (Molina-Cano et al., 2005; Orabi et al., 2007); subsistence farming practice that rely on landraces (Demissie and Bjornstad, 1997; Lakew et al., 1997;Teshome et al., 1997; Hadado et al., 2010; Abebe et al., 2010), the geographic and agro-climatic variability of the area affecting adaptability of landraces (Megersa et al., 2019; Taye et al., 2019; Yang et al., 2020). The barley growing region of Ethiopia is characterized by a very diverse topography with gorges and hills creating niche or variable micro-environments of barley production (Demissie and Bjornstad, 1997; Lakew et al., 1997; Hadado et al., 2009). The local farmers are cultivating divers landraces for different socio-cultural uses (Shewayrga and Sopade, 2011; Khan et al., 2012) and also served as an insurance to avert risk of crop failure as well as to meet niche environments. Consequently, farmers of the area have been maintaining invaluable diversity for generations. It has been documented that farmers make conscious decision and management efforts based on agro-ecological condition and end-use to maintain landraces diversity (Teshome et al., 1997; Seboka and van Hintum, 2006). Preferences of different landraces for various end-uses like tworowed (e.g. Koloroasted barley used as snak), roasted grain (milky dough stage), local fermented or non-fermented beverages (e.g. Qaribo, Shameta and Tela), occasional dish (e.g. Chuko) and daily dishes (e.g. Injera) affect the selection and maintenance of landraces, which in turn affect genetic diversity (Shewayrga and Sopade, 2011). Phenotypic study of a larger sample of 585 accessions (from which the 384 accessions were subsampled) indicated a high variability for both quantitative and qualitative traits (Dido et al., 2020a; Dido et al., 2020a).

\section{Partitioning Genetic diversity and population Structure}

The barley genotypes used in this study are representative of collection from different barley producing Zones in Ethiopia. The analysis of population structure assigned all the 384 barley genotypes into seven clusters. All the three methods used viz. STRUCTURE, UPGMA clustering, and Discriminant analysis of principal component (DAPC) or PCoA; consistently recovered the same seven groups. The consistency of grouping using these methods has also been observed in earlier studies on different crop species (Tascioglu et al., 2016; Ya et al., 2017; Ketema et al., 2020). The differentiation of the population into different subpopulations by fastSTRUCTURE is based on frequencies of relatedness of the genotypes to each of the subpopulations as hypothesized (Nielsen et al., 2014; Chao et al., 2010).

In this, we expected to have more than 10 groupings, corresponding to the landraces geographic origin. This expectation was based on the conviction that the barley landraces are grown in diverse agro-ecologies of Ethiopia, ranging from lowland to high mountainous areas with diverse ethnic groups practicing unique socio-cultural activities, are genetically more diverse than newly introduced modern cultivars (Lakew et al., 1997; Hadado et al., 2009; Abebe et al., 2010). However, contrary to our expectation, the result obtained did not yield such distinct strict clusters based on geographic origin, but rather admixture (Table 5) was observed among all seven subpopulations. Substantial admixture in the population was indicated by the first principal component explaining only $23.10 \%$ of the total genotypic variation. We observed that cluster III had the highest proportion of SD (Sidama) genotypes (33.33\%) and WL (Wellega) genotypes (25.00\%) comprising highest proportions of landraces (16.80) followed by cluster VII (14.92\%) which had the highest proportion of landraces (33.33\%) from MT ( ) zone. This admixture could be due to gene flow facilitated by seed exchange among barley farmers in various agro-ecologies in shared market and also long distance trade (Desmae et al., 2016).

\section{Conclusion And Implication For Conservation And Use Of Barley Landrace For Improvement}

Genetic information from this detailed study has provided first-hand data of the genetic diversity and structure of Ethiopian $H$. vulgare populations in its cultivation ranges distributed across various agro-ecologies which are crucial for developing strategy for conservation and use to improve the productivity of the crop. Among 15 populations from 15 localities across the majority of barley producing Zones, 478 alleles were obtained in total with an average of 9.755 alleles per locus. Natural populations maintained moderate to low genetic diversity levels, high gene flow and low genetic differentiation among populations. AMOVA also demonstrated major variation existed within populations, which is attributed to high gene flow facilitated by seed exchange. From the results of STRUCTURE analysis, 15 natural populations were categorized into seven groups by PCoA cluster analysis, which could possibly be considered as seven management units for the purpose of conservation. The largest number of populations should be saved by on-farm conservation and ex situ conservation measures, taking precedence over those with genetic diversity and differentiation.

In this study, the markers used allowed investigation of population structure, genetic diversity and proposed germplasm collection and a conservation strategy for $H$. vulgare L. Important information about genetic structure was provided by these markers, which significantly contribute to future improvements and breeding plans for the crop. The genetic diversity, population structure and genetic relationships between the populations through SSR analysis will be helpful for crop breeding to improve its productivity. To conclude, these results provide value as an important resource to study genetic diversity and support conservation and use the marker to initiate molecular breeding for future improvement.

\section{Declarations}

\section{Authors' contribution}

Conceptualization, investigation, data collection analysis and visualization, AAD; Methodology, AAD and KT; Resource and Project administration, KT; Supervision, BJKS, MSRK, DTD, KT; Validation, BJKS, KT, DTD, and MSRK; Data analysis, AAD and EA; Writing-original draft, AAD and KT; Reviewing and editing, KT, DTD, BJKS, MSRK and EA. All authors commented on previous versions of the manuscript and finally they read and approved the final manuscript. 


\section{Acknowledgments}

The authors are indebted to numerous individuals for valuable suggestions during the development of this project. We would like to thank Ethiopian Biotechnology Institute for fully funding the research, Ethiopian Biodiversity Institute (EBI) and Sinana Agricultural Research Center for provision of landraces cultivars, respectively. Mr. Keyru is acknowledged for his technical support in laboratory arrangements, DNA extraction and pertinent data collection processes.

Funding: This research work was supported by the Ethiopian Biotechnology Institute.

Conflict of interest statement: The authors declare that the research was conducted in the absence of any commercial or financial relationships that could be construed as a potential conflict of interest.

\section{References}

Abebe TD, Bauer AM, Léon J (2010) Morphological diversity of Ethiopian barleys (Hordeum vulgare L.) in relation to geographic regions and altitudes. Hereditas 147:154-164.

Alam AKMM, Begum M, Chaudhury MJA, et al. (2007) D2 analysis in early maturity hull-less barley (Hordeum vulgare L.). Int. J. Sustain. Crop Production 2:15-17.

Amanda B (2008) The biology of Hordeum vulgare L. (Barley). Second edition, The University of Adelaide, Australia.

Asfaw Z (1989) Relationships between spike morphology, hordein and altitude within Ethiopian barley, Hordeum vulgare (Poaceae). Hereditas 110:203209.

Badiane FA, Gowda BS, Cissé N, et al (2012) Genetic relationship of cowpea (Vigna unguiculata) varieties from Senegal based on SSR markers. Genet. Mol. Res. 11:292-304.

Barkley NA, Dean RE, Pittman RN, et al (2007) Genetic diversity of cultivated and wild-type peanuts evaluated with M13-tailed SSR markers and sequencing. Genet Res 89:93-106.

Becker J, Heun M (1995) Barley microsatellites: allele variation and mapping. Plant Mol Biol 27:835-845

Bekele E (1983) Allozyme genotypic composition and genetic distance between the Ethiopian landrace populations of barley. Hereditas $98: 259-267$.

Bellucci E, Bitocchi E, Rau D, et al (2013) Population structure of barley landrace populations and gene flow with modern varieties. PLoS ONE 8: e83891.

Botstein, D, White RL, Skalnick MH, et al. (1980) Construction of a genetic linkage map in man using restriction fragment length polymorphism, Am J Hum Genet 32:314-331.

Chao S, Dubcovsky J, Dvorak J, et al. (2010) Population and genome-specific patterns of linkage disequilibrium and SNP variation in spring and winter wheat (Triticum aestivum L.). BMC Genomics 11:727.

Che YH, Li, HJ, Yang YP, et al (2008) On the use of SSR markers for the genetic characterization of the Agropyron cristatum (L.) Gaertn. in Northern China. Genetic Resource and Crop Evolution 55:389-396.

Chen ZW, Lu RJ, Zou L, et al (2012) Genetic diversity analysis of barley landraces and cultivars in the Shanghai region of China. Genet. Mole. Res. 11:644650.

Chen R, Shimono A, Aono M, et al. (2020) Genetic diversity and population structure of feral rapeseed (Brassica napus L.) in Japan. PLoS ONE 15(1): e0227990.

Demissie A, Bjornstad A (1997) Geographical, altitude and agro-ecological differentiation of isozyme and hordein genotypes of landrace barleys from Ethiopia: implication to germplasm and conservation. Genetic Resources and Crop Evolution 44:43-55.

Desmae H, Jordan DR, Godwin ID (2016) DNA markers reveal genetic structure and localized diversity of Ethiopian sorghum landraces. African Journal of Biotechnology 15(41): 2301-2311

Dido AA., Degefu DT, Singh BJK, et al. (2020a) Multivariate analysis of quantitative characters variability in Ethiopian barley (Hordeum vulgare L.) landrace: based on regions and altitude. Genetika, 52(2):597-620. 
Dido AA, Singh BJK, Krishna MSR, et al. (2020b) Variability analysis for qualitative characters in Ethiopian barley (Hordeum vulgare L.) landraces. Res. on Crops 21(2):355-363.

Earl DA, vonHoldt BM (2012) STRUCTURE HARVESTER: a website and program for visualizing STRUCTURE output and implementing the Evanno method. Conserv Genet Resour 4:359-61.

Eleuch L, Jilal A, Grando S, et al. (2008) Genetic diversity and association analysis for salinity tolerance, heading date and plant height of barley germplasm using simple sequence repeat markers. J Integr Plant Biol 50:1004-1014.

El-Esawi MA, Germaine K, Bourke P, et al. (2016) Genetic diversity and population structure of Brassica oleracea germplasm in Ireland using SSR markers. Comptes Rendus Biologies 339(3-4).

Evanno G, Regnaut S, Goudet J (2005) Detecting the number of clusters of individuals using the software STRUCTURE: a simulation study. Mol Ecol 14:2611-2620.

Guo XM, Gao AN, Liu WH, et al. (2011) Evaluation of genetic diversity, population structure, and linkage disequilibrium among elite Chinese wheat (Triticum aestivum L.) cultivars. Aust J Crop Sci 15:1167-1172.

Graner A, Jahoor A, Schondelmaier J, et al. (1991) Construction of an RFLP map of barley. Theor Appl Genet 83:250-256

Hadado TT, Rau D, Bitocchi E, et al. (2009) Genetic Diversity of barley (Hordeum vulgare L.) landraces from the central highlands of Ethiopia: comparison between the Belg and Meher growing seasons using morphological traits. Genet Resour Crop Evol 56:1131-1148.

Hearnden PR, Eckermann PJ, McMichael GL et al. (2007) A genetic map of 1,000 SSR and DArT markers in a wide barley cross. Theor Appl Genet 115:383. https://doi.org/10.1007/s00122-007-0572-7

Hong Y, Chen X, Liang X et al (2010) A SSR-based composite genetic linkage map for the cultivated peanut (Arachis hypogaea L.) genome. BMC Plant Biol 10:17.

Jakobsson M, Rosenberg N (2007) CLUMPP: a cluster matching and permutation program for dealing with label switching and multimodality in analysis of population structure. Bioinformatics 23(14):1801-1806.

Jombart T, Devillard S, Balloux F (2010) Discriminant analysis of principal components: A new method for the analysis of genetically structured populations. BMC Genetics 11(1):94.

Kamvar ZN, Tabima JF, Grünwald NJ (2014) Poppr. an R package for genetic analysis of populations with clonal, partially clonal, and/or sexual reproduction. PeerJ 2: e281.

Kefayati S, Ikhsan AS, Sutyemez M et al. (2019) First simple sequence repeat-based genetic linkage map reveals a major QTL for leafing time in walnut (Juglans regia L.). Tree Genetics and Genomes 15:13. https://doi.org/10.1007/s11295-019-1318-9

Khan SM, Hashimi M, Khan KU, et al. (2012) Barley (Hordeum vulgare L.) A Prophetic Food Mentioned in Ahadith and its Ethnobotanical Importance. American-Eurasian J Agric Environ Sci 12(7):835-841.

Karp A, Edwards KJ (1995) Molecular techniques in the analysis of the extent and distribution of genetic diversity. IPGRI Workshop on Molecular Genetic Tools in Plant Genetic Resources, 9-11 October, Rome, IPGRI

Ketema S, Tesfaye B, Keneni G, et al. (2020) DArTSeq SNP-based markers revealed high genetic diversity and structured population in Ethiopian cowpea (Vigna unguiculata L. Walp) germplasms. PLoS ONE 15(10): e0239122.

Kleinhofs A, Kilian A, Saghai Maroof MA, et al. (1993) A molecular, isozyme and morphological map of the barley (Hordeum vulgare) genome. Theor Appl Genet 86:705-712

Lakew B, Semeane T, Alemayehu F, et al (1997) Exploiting the diversity of barley landraces in Ethiopia. Genet Resour Crop Evol 44:109-116.

Li JZ, Sjakste TG, Roder MS, et al. (2003) Development and genetic mapping of 127 new microsatellite markers in barley. Theor Appl Genet 107:10211027

Li RY, Zhang H, Zhou XC, et al. (2010) Genetic diversity in Chinese sorghum landraces revealed by chloroplast simple sequence repeats. Genet Resour Crop Evol 57:1-15.

Liu K, Muse SV (2005) PowerMarker: An integrated analysis environment for genetic marker analysis. Bioinformatics 21:2128-2129.

Matus IA, Hayes PM (2002) Genetic diversity in three groups of barley germplasm assessed by simple sequence repeats. Genome 45:1095-1106. 
Megersa G, Tesfaye K, Getnet M, et al. (2019) Rainfall Variability and its Implications for Wheat and Barley Production in Central Ethiopia. Ethiopian J Crop Sci 7(2): 89-111.

Molina-Cano, JL, Russell JR, Moralejo MA, et al. (2005). Chloroplast DNA microsatellite analysis supports a polyphyletic origin for barley. Theor Appl Genet 110(4):613-619.

Nielsen NH, Backes G, Stougaard J, et al. (2014) Genetic Diversity and Population Structure Analysis of European Hexaploid Bread Wheat (Triticum aestivum L.) Varieties. PLoS ONE 9(4): e94000.

Orabi J, Backes G, Wolday A et al. (2007) The Horn of Africa as a centre of barley diversification and a potential domestication site. Theor Appl Genet 114:1117-1127.

Orabi J, Ahmed J, Gunter B (2014) Changes in allelic frequency over time in European bread wheat (Triticum aestivum L.) varieties revealed using DArT and SSR markers. Euphytica DOI 10.1007/s10681-014-1080-x

Ould Med Mahmouda M, Hamzaa S (2009) Genetic diversity in local barley accessions collected from different geographical regions of Tunisia. Plant Genetic Resources 7:169-176.

Pasam RK, Sharma R, Walther A, et al. (2014) Genetic diversity and population structure in a legacy collection of spring barley landraces adapted to a wide range of climates. PLOS ONE, 9 (2014) e116164.

Peakall R., Smouse P.E. GenAlEx 6.5 (2012) Genetic analysis in Excel. Population genetic software for teaching and research-An update. Bioinformatics. 28:2537-2539.

Pritchard JK, Stephens M, Donnelly P (2000) Inference of population structure using multilocus genotype data. Genetics 155:945-59.

Ren X, Jiang H, Yan Z, et al. (2014) Genetic diversity and population structure of the major peanut (Arachis hypogaea L.) cultivars grown in China by SSR markers. PLoS ONE 9:e88091.

Rosenberg NA (2004) DISTRUCT: a program for the graphical display of population structure. Molecular Ecology Resources, 4(1):137-138.

Rousset F (2008) Genepop'007: a complete re-implementation of the genepop software for Windows and Linux. Molecular Ecology Resources 8:103-106.

Saghai Maroof M, Biyashev RM, Yang GP, et al. (1994) Extraordinarily polymorphic microsatellite DNA in barley: species diversity, chromosomal locations, and population dynamics. Proc Natl Acad Sci USA 91:5466-5470

Seboka B, van Hintum T (2006) The dynamics of on-farm management of sorghum in Ethiopia: Implication for the conservation and improvement of plant genetic resources. Genet Res Crop Evol 53(7):1385-1403.

Shewayrga H, Sopade PA (2011) Ethnobotany, diverse food uses, claimed health benefits and implications on conservation of barley landraces in North Eastern Ethiopia highlands. J Ethnobiol Ethnomedicine 7(19):1-15.

Shiferaw E, Pe ME, Porceddu E, et al. (2012) Exploring the genetic diversity of Ethiopian grass pea (Lathyrus sativus L.) using EST-SSR markers. Mol Breed DOI 10.1007/s11032-011-9662-y.

Song QJ, Shi JR, Singh S et al. (2005) Development and mapping of microsatellite (SSR) markers in wheat. Theor Appl Genet 110:550-560. https://doi.org/10.1007/s00122-004-1871-x

Struss D, Plieske J (1998) The use of microsatellite markers for detection of genetic diversity in barley populations. Theor Appl Genet 97:308-315

Tara SC, Bhat KV, Bharadwaj C, et al. (2006) AFLP analysis of genetic diversity in Indian soybean (Glycine max (L.) Merr.) varieties. Genet Resour Crop Evol 53:1069-1079.

Tascioglu T, Metin OK, Aydin Y, et al. (2016) Genetic diversity, population structure and linkage disequilibrium in bread wheat (Triticum aestivum) Biochem Genet 54:421-437.

Taye M, Simane B, Benjamin FZ, et al. (2019) Rainfall Variability across the Agro-Climatic Zones of a Tropical Highland: The Case of the Jema Watershed, Northwestern Ethiopia. Environments 6(118). Doi: 103390/environments6110118

Teshome A, Baum BR, Fahrig L, et al. (1997) Sorghum (sorghum bicolor(L.) Moench) landrace variation and classification in North Shewa and South Welo, Ethiopia. Euphytica 97:255-263.

Varshney RK, Zhang H, Potokina E, et al. (2004) A simple hybridization-based strategy for the generation of non-redundant EST collections-A case study in barley (Hordeum vulgare L.). Plant Science 167(3):629-634.

Varshney RK, Graner A, Sorrells ME (2005) Genic microsatellite markers in plants: Features and applications. Trends Biotech. 23:48-55.

Page 10/23 
Varshney RK, Marcel TC, Ramsay L, et al (2007) A high density barley microsatellite consensus map with 775 SSR loci. Theor Appl Genet 114(6):10911103.

Varshney RK, Bertioli DJ, Moretzsohn MC, et al. (2009) The first SSR-based genetic linkage map for cultivated groundnut (Arachis hypogaea L.). Theor Appl Genet 118:729-739.

von Bothmer R, Jacobsen N (1980) A taxonomic revision of Hordeum secalinum and H. capense. Bot. Tidsskr. 74: $223-235$.

von Bothmer R, Jacobsen N, Jørgensen RB, et al. (1982) Revision of the Hordeum pusillum group

Nord. J. Bot. 2: 307-321.

von Bothmer R, Jacobsen N, Jcirgensen RB (1986) Taxonomy, variation, and relationships in the Hordeum parodii group (Poaceae). - Nord. J. Bot. 6: 399410 .

Wang L, Guan R, Zhang XL, et al. (2006) Genetic diversity of Chinese cultivated soybean revealed by SSR markers. Crop Science 46:1032-1038.

Wang JM, Yang JM, Zhu JH, et al. (2010) Assessment of genetic diversity by simple sequence repeats markers among forty elite varieties in the germplasm for malting barley breeding. J. Zhejiang Univ. Sci. B 11(10) (2010) 792-800.

Wen ZX, Ding YL, Zhao TN, et al. (2009) Genetic diversity and peculiarity of annual wild soybean (G. soja Sieb. et Zucc.) from various eco-regions in China. Theor Appl Genet 119:371-381.

Ya N, Raveendar S, Bayarsukh N, et al. (2017) Genetic diversity and population structure of Mongolian wheat based on SSR markers: implications for conservation and management. Plant Breed Biotech. 5:213-220.

Zane L, Bargelloni L, Patarnello T (2002) Strategies for microsatellite isolation: A review. Mol Ecol 11:1-16.

\section{Tables}

Table 1. Genetic parameters of the 49 polymorphic simple sequence repeat markers used in this study across the genome of 384 barley accessions 


\begin{tabular}{|c|c|c|c|c|c|c|c|c|c|c|c|c|c|c|}
\hline Locus name & Maf & $\mathrm{Na}$ & $\mathrm{Ng}^{\mathrm{b}}$ & Npa & $\mathrm{Ne}$ & I & $\mathrm{He}$ & Ho & $\mathrm{F}_{\mathrm{IS}}$ & $F_{I T}$ & $\mathrm{~F}_{\mathrm{ST}}$ & $\mathrm{Nm}$ & PIC & HWEpv \\
\hline GMS021 & 0.612 & 13 & 26 & 2 & 3.258 & 0.781 & 0.503 & 0.353 & 0.206 & 0.303 & 0.040 & 6.000 & 0.581 & 0.000 \\
\hline Bmag0211 & 0.766 & 8 & 12 & 3 & 2.000 & 0.460 & 0.560 & 0.390 & 0.047 & 0.054 & 0.023 & 10.620 & 0.770 & 0.000 \\
\hline HVM20 & 0.729 & 16 & 21 & 5 & 1.815 & 0.890 & 0.420 & 0.112 & 0.127 & 0.148 & 0.079 & 2.915 & 0.630 & 0.000 \\
\hline HVHVA1 & 0.737 & 6 & 25 & 3 & 2.000 & 0.740 & 0.430 & 0.310 & 0.282 & 0.348 & 0.025 & 9.750 & 0.680 & 0.000 \\
\hline WMC1E8 & 0.737 & 18 & 22 & 2 & 1.293 & 0.400 & 0.470 & 0.131 & 0.045 & 0.053 & 0.187 & 1.087 & 0.243 & 0.000 \\
\hline EBmac0501 & 0.732 & 6 & 14 & 2 & 1.600 & 0.370 & 0.400 & 0.290 & 0.268 & 0.455 & 0.045 & 5.306 & 0.630 & 0.000 \\
\hline EBmac0560 & 0.688 & 7 & 31 & 1 & 2.377 & 0.550 & 0.560 & 0.390 & 0.244 & 0.346 & 0.028 & 8.679 & 0.550 & 0.000 \\
\hline HVBKASI & 0.617 & 12 & 21 & 4 & 2.848 & 0.700 & 0.460 & 0.330 & 0.042 & 0.043 & 0.135 & 1.602 & 0.450 & 0.000 \\
\hline HVM36 & 0.729 & 8 & 27 & 0 & 1.727 & 0.660 & 0.370 & 0.270 & 0.095 & 0.078 & 0.018 & 13.639 & 0.740 & 0.000 \\
\hline HVM54 & 0.740 & 6 & 19 & 2 & 3.215 & 0.460 & 0.510 & 0.380 & -0.013 & 0.062 & 0.062 & 3.782 & 0.650 & 0.124 \\
\hline Bmac0093 & 0.674 & 14 & 21 & 0 & 3.350 & 0.640 & 0.400 & 0.270 & -1.000 & -1.000 & 0.000 & & 0.770 & 0.000 \\
\hline EBmac0615 & 0.706 & 8 & 15 & 1 & 1.512 & 0.530 & 0.580 & 0.420 & 0.151 & 0.054 & 0.043 & 5.564 & 0.860 & 0.000 \\
\hline Bmac0129b & 0.643 & 9 & 27 & 0 & 1.527 & 0.460 & 0.260 & 0.120 & 0.087 & 0.073 & 0.145 & 1.474 & 0.595 & 0.000 \\
\hline HvXan & 0.745 & 7 & 14 & 0 & 2.281 & 0.500 & 0.470 & 0.330 & 0.240 & 0.039 & 0.055 & 4.295 & 0.640 & 0.000 \\
\hline GMS116A & 0.531 & 11 & 19 & 1 & 1.047 & 0.450 & 0.640 & 0.320 & 0.155 & 0.028 & 0.046 & 5.185 & 0.750 & 0.000 \\
\hline HVLTPPB & 0.536 & 14 & 20 & 1 & 3.712 & 0.710 & 0.510 & 0.420 & 0.244 & 0.625 & 0.048 & 4.958 & 0.780 & 0.000 \\
\hline HVM44 & 0.612 & 6 & 24 & 2 & 1.990 & 0.470 & 0.380 & 0.290 & 0.135 & 0.160 & 0.039 & 6.160 & 0.540 & 0.000 \\
\hline Bmac0209 & 0.703 & 14 & 12 & 4 & 1.444 & 0.500 & 0.540 & 0.390 & 0.161 & 0.175 & 0.090 & 2.528 & 0.860 & 0.000 \\
\hline WMS6 & 0.719 & 8 & 30 & 0 & 2.585 & 0.770 & 0.490 & 0.370 & 0.056 & 0.089 & 0.015 & 16.417 & 0.770 & 0.000 \\
\hline Bmac0067 & 0.701 & 13 & 15 & 3 & 2.000 & 0.430 & 0.510 & 0.360 & 0.150 & 0.157 & 0.013 & 18.981 & 0.560 & 0.000 \\
\hline Bmag0905 & 0.708 & 8 & 37 & 0 & 2.045 & 0.380 & 0.520 & 0.270 & -1.000 & -1.000 & 0.000 & & 0.630 & 0.000 \\
\hline HVMLOH1A & 0.708 & 10 & 14 & 3 & 1.413 & 0.600 & 0.500 & 0.390 & 0.177 & 0.224 & 0.035 & 6.893 & 0.650 & 0.000 \\
\hline GMS089 & 0.628 & 10 & 19 & 2 & 2.400 & 0.950 & 0.540 & 0.390 & 0.161 & 0.301 & 0.025 & 9.750 & 0.675 & 0.000 \\
\hline HVRCABG & 0.703 & 11 & 20 & 2 & 1.964 & 0.570 & 0.540 & 0.410 & 0.147 & 0.072 & 0.043 & 5.564 & 0.735 & 0.000 \\
\hline HVM40 & 0.721 & 8 & 23 & 1 & 2.367 & 0.350 & 0.420 & 0.290 & -0.204 & 0.143 & 0.025 & 9.750 & 0.835 & 0.013 \\
\hline HVKNOX3 & 0.716 & 3 & 19 & 0 & 2.993 & 1.680 & 0.510 & 0.350 & -0.472 & 0.063 & 0.044 & 5.432 & 0.810 & 0.027 \\
\hline EBmac0679 & 0.674 & 12 & 36 & 3 & 1.337 & 0.690 & 0.450 & 0.340 & 0.135 & 0.190 & 0.030 & 8.001 & 0.770 & 0.000 \\
\hline HVM67 & 0.664 & 8 & 21 & 3 & 1.266 & 0.540 & 0.430 & 0.270 & 0.140 & 0.161 & 0.046 & 5.185 & 0.830 & 0.000 \\
\hline HVDHN7 & 0.602 & 9 & 22 & 1 & 1.872 & 0.730 & 0.390 & 0.230 & 0.149 & 0.306 & 0.023 & 10.620 & 0.760 & 0.000 \\
\hline HVACL1 & 0.609 & 11 & 20 & 4 & 1.225 & 0.560 & 0.510 & 0.370 & 0.574 & 0.061 & 0.075 & 3.083 & 0.695 & 0.000 \\
\hline HVLEU & 0.677 & 10 & 25 & 3 & 1.932 & 0.600 & 0.540 & 0.360 & 0.135 & 0.145 & 0.152 & 1.395 & 0.770 & 0.000 \\
\hline Bmag0337 & 0.651 & 10 & 15 & 6 & 1.468 & 0.930 & 0.420 & 0.320 & 0.062 & 0.370 & 0.028 & 8.679 & 0.859 & 0.000 \\
\hline EBmac0518 & 0.784 & 13 & 24 & 2 & 1.966 & 0.210 & 0.480 & 0.200 & 0.311 & 0.177 & 0.079 & 2.915 & 0.830 & 0.000 \\
\hline Bmag0812 & 0.557 & 9 & 12 & 0 & 3.215 & 0.500 & 0.470 & 0.350 & -0.077 & 0.372 & 0.049 & 4.852 & 0.820 & 0.021 \\
\hline Bmag0222 & 0.693 & 10 & 31 & 4 & 2.897 & 0.500 & 0.320 & 0.320 & 0.054 & 0.361 & 0.024 & 10.167 & 0.770 & 0.000 \\
\hline GMS006 & 0.750 & 6 & 15 & 2 & 1.884 & 0.960 & 0.370 & 0.320 & -0.334 & 0.045 & 0.025 & 9.750 & 0.830 & 0.200 \\
\hline HVM65 & 0.750 & 13 & 26 & 1 & 3.250 & 0.500 & 0.390 & 0.270 & 0.154 & 0.177 & 0.048 & 4.958 & 0.685 & 0.000 \\
\hline Bmac0316 & 0.622 & 5 & 26 & 0 & 2.000 & 1.650 & 0.570 & 0.330 & 0.051 & 0.320 & 0.032 & 7.563 & 0.825 & 0.000 \\
\hline Bmag0173 & 0.680 & 11 & 21 & 3 & 2.986 & 0.490 & 0.530 & 0.340 & -1.000 & -1.000 & 0.000 & & 0.790 & 0.000 \\
\hline Bmac0040 & 0.711 & 18 & 15 & 1 & 2.518 & 0.806 & 0.540 & 0.340 & 0.260 & 0.521 & 0.026 & 9.365 & 0.885 & 0.000 \\
\hline HvWaxy4b & 0.669 & 7 & 30 & 1 & 2.000 & 0.580 & 0.430 & 0.240 & 0.071 & 0.051 & 0.038 & 6.329 & 0.830 & 0.000 \\
\hline
\end{tabular}




\begin{tabular}{|c|c|c|c|c|c|c|c|c|c|c|c|c|c|c|}
\hline EBmac0874 & 0.612 & 6 & 18 & 2 & 1.392 & 0.830 & 0.510 & 0.380 & 0.531 & 0.041 & 0.109 & 2.044 & 0.770 & 0.000 \\
\hline Bmag0007 & 0.773 & 12 & 24 & 3 & 1.732 & 0.330 & 0.460 & 0.270 & 0.047 & 0.059 & 0.130 & 1.673 & 0.860 & 0.000 \\
\hline Bmac0273e & 0.781 & 6 & 19 & 3 & 1.983 & 0.380 & 0.540 & 0.350 & -1.000 & -1.000 & 0.000 & & 0.790 & 0.000 \\
\hline Bmag0135 & 0.771 & 8 & 22 & 0 & 1.294 & 0.530 & 0.480 & 0.370 & 0.077 & 0.081 & 0.039 & 6.160 & 0.760 & 0.000 \\
\hline HVCMA & 0.609 & 13 & 29 & 1 & 1.610 & 1.530 & 0.550 & 0.290 & 0.142 & 0.040 & 0.065 & 3.596 & 0.760 & 0.000 \\
\hline HvID & 0.760 & 8 & 21 & 2 & 1.246 & 0.570 & 0.590 & 0.320 & 0.742 & 0.043 & 0.031 & 7.815 & 0.740 & 0.000 \\
\hline HVM04 & 0.776 & 7 & 19 & 2 & 2.277 & 0.560 & 0.490 & 0.310 & -0.027 & -0.011 & 0.023 & 10.620 & 0.780 & 0.017 \\
\hline Bmag0217 & 0.740 & 12 & 27 & 1 & 1.233 & 0.710 & 0.540 & 0.290 & 0.098 & 0.035 & 0.037 & 6.507 & 0.820 & 0.000 \\
\hline Total & & 478 & 1065 & 92 & & & & & & & & & & \\
\hline Mean & 0.689 & 9.755 & 21.735 & 1.878 & 2.068 & 0.647 & 0.479 & 0.417 & 0.037 & 0.074 & 0.049 & 6.613 & 0.727 & \\
\hline SD & & 3.496 & 3.088 & & 0.681 & 0.228 & 0.073 & 0.069 & & & 0.197 & & 0.122 & \\
\hline
\end{tabular}

MAF = Major allele frequency, $\mathrm{Na}=$ number of alleles per locus; $\mathrm{Ng}=$ Number of genotypes where each locus amplified alleles; Npa = Number of private (unique) alleles, $\mathrm{Ne}=$ number of effective alleles; I = Shannon's information index; $\mathrm{He}=$ expected heterozygosity; Ho = observed heterozygosity; $\mathrm{F}$, inbreeding coefficient over all populations $\left(F_{I S}\right)$, among populations $\left(F_{I T}\right)$ and within populations $\left(F_{S T}\right)$, Nm: number of migrants, PIC $=$ polymorphism information content, HWE pV, Hardy-Weinberg equilibrium $p$-value based on chi square test (There is a deviation from HWE at $\mathrm{p}<0.05$ )

Table 2. Summary statistics of number of loci per SSR primer combinations, number of alleles per locus, number of unique alleles and polymorphic information content (PIC) 


\begin{tabular}{|c|c|c|c|c|c|c|c|}
\hline \multirow[t]{2}{*}{ SSR primers } & \multirow[t]{2}{*}{$\mathrm{Na}$} & \multirow[t]{2}{*}{ NL } & \multicolumn{5}{|c|}{ Number of unique alleles } \\
\hline & & & Two-rowed & Six-rowed & Cultivars & Total & PIC \\
\hline GMS021 & 13 & 26 & 1 & 1 & 0 & 2 & 0.581 \\
\hline Bmag0211 & 8 & 12 & 1 & 1 & 0 & 2 & 0.770 \\
\hline HVM20 & 16 & 21 & 1 & 1 & 1 & 3 & 0.630 \\
\hline HVHVA1 & 6 & 25 & 2 & 1 & 0 & 3 & 0.680 \\
\hline WMC1E8 & 18 & 22 & 1 & 1 & 0 & 2 & 0.243 \\
\hline EBmac0501 & 6 & 14 & 0 & 2 & 0 & 2 & 0.630 \\
\hline EBmac0560 & 7 & 31 & 2 & 0 & 1 & 3 & 0.550 \\
\hline HVBKASI & 12 & 21 & 0 & 1 & 1 & 2 & 0.450 \\
\hline HVM36 & 8 & 27 & 1 & 1 & 0 & 2 & 0.740 \\
\hline HVM54 & 6 & 19 & 1 & 0 & 0 & 1 & 0.650 \\
\hline Bmac0093 & 14 & 21 & 0 & 1 & 1 & 2 & 0.770 \\
\hline EBmac0615 & 8 & 15 & 0 & 1 & 0 & 1 & 0.860 \\
\hline Bmac0129b & 9 & 27 & 1 & 0 & 1 & 2 & 0.595 \\
\hline HvXan & 7 & 14 & 0 & 1 & 0 & 1 & 0.640 \\
\hline GMS116A & 11 & 19 & 1 & 0 & 1 & 2 & 0.750 \\
\hline HVLTPPB & 14 & 20 & 0 & 1 & 0 & 1 & 0.780 \\
\hline HVM44 & 6 & 24 & 0 & 0 & 0 & 0 & 0.540 \\
\hline Bmac0209 & 14 & 12 & 1 & 0 & 0 & 1 & 0.860 \\
\hline WMS6 & 8 & 30 & 0 & 1 & 0 & 1 & 0.770 \\
\hline Bmac0067 & 13 & 15 & 2 & 0 & 1 & 3 & 0.560 \\
\hline Bnag0905 & 8 & 37 & 1 & 0 & 0 & 1 & 0.630 \\
\hline HVMLOH1A & 10 & 14 & 0 & 1 & 1 & 2 & 0.650 \\
\hline GMS089 & 10 & 19 & 0 & 1 & 0 & 1 & 0.675 \\
\hline HVRCABG & 11 & 20 & 1 & 1 & 1 & 3 & 0.735 \\
\hline HVM40 & 8 & 23 & 1 & 0 & 1 & 2 & 0.835 \\
\hline HVKNOX3 & 3 & 19 & 0 & 1 & 0 & 1 & 0.810 \\
\hline EBmac0679 & 12 & 36 & 0 & 1 & 1 & 2 & 0.770 \\
\hline HVM67 & 8 & 21 & 2 & 1 & 0 & 3 & 0.830 \\
\hline HVDHN7 & 9 & 22 & 0 & 0 & 0 & 0 & 0.760 \\
\hline HVACL1 & 11 & 20 & 1 & 1 & 0 & 2 & 0.695 \\
\hline HVLEU & 10 & 25 & 2 & 0 & 0 & 2 & 0.770 \\
\hline Bmag0337 & 10 & 15 & 1 & 0 & 1 & 2 & 0.859 \\
\hline EBmac0518 & 13 & 24 & 0 & 1 & 0 & 1 & 0.830 \\
\hline Bmag0812 & 9 & 12 & 1 & 1 & 0 & 2 & 0.820 \\
\hline Bmag0222 & 10 & 31 & 2 & 0 & 0 & 2 & 0.770 \\
\hline GMS006 & 6 & 15 & 1 & 1 & 0 & 2 & 0.830 \\
\hline HVM65 & 13 & 26 & 1 & 0 & 1 & 2 & 0.685 \\
\hline Bmac0316 & 5 & 26 & 1 & 1 & 0 & 2 & 0.825 \\
\hline Bmag0173 & 11 & 21 & 1 & 1 & 0 & 2 & 0.790 \\
\hline Bmac0040 & 18 & 15 & 3 & 1 & 1 & 5 & 0.885 \\
\hline HvWaxy4b & 7 & 30 & 0 & 0 & 0 & 0 & 0.830 \\
\hline
\end{tabular}

Page 14/23 


\begin{tabular}{|llllllll|}
\hline EBmac0874 & 6 & 18 & 2 & 1 & 0 & 3 & 0.770 \\
\hline Bmag0007 & 12 & 24 & 0 & 1 & 1 & 2 & 0.860 \\
\hline Bmac0273e & 6 & 19 & 2 & 1 & 0 & 3 & 0.790 \\
\hline Bmag0135 & 8 & 22 & 1 & 0 & 1 & 2 & 0.760 \\
\hline HVCMA & 13 & 29 & 1 & 1 & 0 & 2 & 0.760 \\
\hline HvID & 8 & 21 & 1 & 1 & 0 & 2 & 0.740 \\
\hline HVM04 & 7 & 19 & 0 & 0 & 1 & 1 & 0.780 \\
Bmag0217 & 12 & 27 & 2 & 0 & 0 & 2 & 0.820 \\
Mean & 9.755 & 21.735 & 0.878 & 0.653 & 0.347 & 1.878 & 0.727 \\
Total & $\mathbf{4 7 8}$ & $\mathbf{1 0 6 5}$ & $\mathbf{4 3}$ & $\mathbf{3 2}$ & $\mathbf{1 7}$ & $\mathbf{9 2}$ & \\
\hline Percent & & & $\mathbf{4 6 . 7 4}$ & $\mathbf{3 4 . 7 8}$ & $\mathbf{1 8 . 4 8}$ & & \\
\hline
\end{tabular}

$\mathrm{Na}=$ Number of alleles per locus, $\mathrm{NL}=$ Number of loci per SSR primer combinations.

Table 3. Genetic parameter estimates based on 49 SSRs among barley subpopulations

\begin{tabular}{|c|c|c|c|c|c|c|c|c|c|c|c|c|}
\hline Population & $\mathbf{N}$ & $\mathrm{Na}$ & $\mathrm{Npa}$ & $\mathrm{Ne}$ & $\mathrm{He}$ & Ho & I & h & uh & $F_{I S}$ & $\operatorname{Ar}$ & $\% \mathrm{PL}$ \\
\hline \multicolumn{13}{|c|}{ Based on Zones of origin } \\
\hline AR & 51 & 10.670 & 9 & 1.783 & 0.356 & 0.699 & 0.624 & 0.434 & 0.443 & 0.164 & 2.217 & 100.00 \\
\hline BL & 42 & 8.787 & 8 & 1.738 & 0.239 & 0.589 & 0.609 & 0.419 & 0.430 & 0.171 & 2.278 & 100.00 \\
\hline GG & 22 & 5.439 & 2 & 1.646 & 0.350 & 0.610 & 0.560 & 0.378 & 0.396 & -0.186 & 1.500 & 100.00 \\
\hline GJ & 47 & 9.833 & 8 & 1.713 & 0.415 & 0.668 & 0.598 & 0.410 & 0.419 & 0.151 & 2.667 & 100.00 \\
\hline GN & 29 & 6.067 & 6 & 1.723 & 0.503 & 0.684 & 0.597 & 0.410 & 0.425 & 0.153 & 2.121 & 100.00 \\
\hline HD & 11 & 2.301 & 2 & 1.537 & 0.448 & 0.650 & 0.487 & 0.323 & 0.355 & 0.155 & 2.302 & 91.84 \\
\hline HR & 35 & 7.322 & 6 & 1.655 & 0.479 & 0.625 & 0.567 & 0.383 & 0.394 & -0.163 & 1.708 & 100.00 \\
\hline JM & 6 & 1.255 & 4 & 1.505 & 0.412 & 0.388 & 0.430 & 0.291 & 0.350 & -0.113 & 1.388 & 75.51 \\
\hline MT & 9 & 1.883 & 0 & 1.502 & 0.339 & 0.610 & 0.477 & 0.311 & 0.350 & -0.158 & 1.201 & 93.88 \\
\hline $\mathrm{SH}$ & 41 & 8.577 & 8 & 1.762 & 0.434 & 0.678 & 0.616 & 0.427 & 0.437 & 0.148 & 2.565 & 100.00 \\
\hline SD & 9 & 1.883 & 7 & 1.774 & 0.228 & 0.477 & 0.603 & 0.421 & 0.474 & -0.141 & 1.557 & 95.92 \\
\hline TC & 34 & 7.113 & 6 & 1.696 & 0.468 & 0.654 & 0.592 & 0.404 & 0.416 & 0.173 & 2.656 & 100.00 \\
\hline TN & 23 & 4.813 & 8 & 1.710 & 0.479 & 0.574 & 0.591 & 0.405 & 0.423 & 0.186 & 2.641 & 100.00 \\
\hline WG & 13 & 2.720 & 6 & 1.723 & 0.212 & 0.450 & 0.592 & 0.406 & 0.440 & 0.166 & 1.378 & 100.00 \\
\hline WL & 12 & 2.510 & 7 & 1.707 & 0.356 & 0.368 & 0.583 & 0.400 & 0.437 & 0.172 & 1.857 & 97.96 \\
\hline Mean & & 31.867 & 6.133 & 1.678 & 0.381 & 0.598 & 0.568 & 0.388 & 0.413 & 0.059 & 2.002 & 97.007 \\
\hline \multicolumn{13}{|c|}{ Based on Breeding Status } \\
\hline Landraces & 376 & 7.380 & 76 & 1.728 & 0.457 & 0.626 & 0.607 & 0.418 & 0.419 & 0.265 & 2.367 & 100.00 \\
\hline Improved & 8 & 9.345 & 16 & 1.760 & 0.512 & 0.509 & 0.59 & 0.412 & 0.471 & 0.217 & 2.023 & 93.88 \\
\hline Mean & & 8.363 & 46.000 & 1.744 & 0.485 & 0.568 & 0.599 & 0.415 & 0.445 & 0.241 & 2.195 & 96.94 \\
\hline \multicolumn{13}{|c|}{ Based on Kernel Row Number } \\
\hline Two-Row & 178 & 3.405 & 32 & 1.714 & 0.651 & 0.598 & 0.601 & 0.412 & 0.414 & 0.251 & 2.124 & 100.000 \\
\hline Six-Row & 186 & 6.751 & 54 & 1.736 & 0.645 & 0.676 & 0.61 & 0.42 & 0.423 & 0.230 & 2.502 & 100.000 \\
\hline Irregular & 20 & 4.321 & 6 & 1.603 & 0.604 & 0.613 & 0.542 & 0.361 & 0.38 & 0.263 & 1.315 & 100.000 \\
\hline Mean & & 4.826 & 30.667 & 1.684 & 0.633 & 0.629 & 0.584 & 0.398 & 0.406 & 0.248 & 1.980 & 100.000 \\
\hline
\end{tabular}


$\mathrm{AR}=\mathrm{Arsi}, \mathrm{BL}=$ Bale, $\mathrm{GG}=$ Gamo Gofa, $\mathrm{GJ}=$ Gojam, $\mathrm{GN}=$ Gonder, $\mathrm{HD}=$ Hadiya, $\mathrm{HR}=$ Hararghe $, \mathrm{JM}=\mathrm{Jimma}, \mathrm{MT}=\mathrm{Metekel}, \mathrm{SH}=\mathrm{Shewa}, \mathrm{SD}=\mathrm{Sidama}, \mathrm{TC}$

$=$ Tigray-Central, $\mathrm{TN}=$ Tigray-Northern, $\mathrm{WG}=$ Wellega, $\mathrm{WL}=$ Wello

$\mathrm{N}=$ Sample size, $\mathrm{Na}=$ Number of different alleles, $\mathrm{Npa}=$ private allele, Ne = number of effective alleles $\left(1 /\left(\mathrm{p}^{\wedge} 2+\mathrm{q}^{\wedge} 2\right), \mathrm{I}=\mathrm{Shannon}\right.$ ' Information Index $=$ $-1 *(p * \operatorname{Ln}(p)+q * \operatorname{Ln}(q)), h=$ Diversity $=1-\left(p^{\wedge} 2+q^{\wedge} 2\right)$, uh $=$ Unbiased Diversity $=(N /(N-1)) * h, A r=$ allele richness, \%PL $=$ Percent polymorphic loci. Where for Haploid Binary data, $p=$ Band Freq. and $q=1-p$.

Table 4. Proportion of membership of each predefined population in each of the clusters obtained at the best K (K=7) from (A) STRUCTURE (B) Discriminant analysis of principal component (DAPC). 


\begin{tabular}{|c|c|c|c|c|c|c|c|c|c|}
\hline \multirow[t]{2}{*}{ Population } & \multirow[t]{2}{*}{ Total accessions } & \multicolumn{8}{|c|}{ Proportion of membership in each cluster (\%) } \\
\hline & & Admixture & Cluster I & Cluster II & Cluster III & Cluster IV & Cluster V & Cluster VI & Cluster VII \\
\hline \multicolumn{10}{|c|}{ (A) STRUCTURE } \\
\hline AR & 51 & 13.73 & 13.73 & 9.80 & 17.65 & 11.76 & 9.80 & 13.73 & 9.80 \\
\hline $\mathrm{BL}$ & 42 & 4.76 & 11.90 & 16.67 & 14.29 & 19.05 & 14.29 & 7.14 & 11.90 \\
\hline GG & 22 & 27.27 & 0.00 & 0.00 & 22.73 & 13.64 & 4.55 & 0.00 & 31.82 \\
\hline GJ & 47 & 10.64 & 17.02 & 14.89 & 10.64 & 12.77 & 14.89 & 10.64 & 8.51 \\
\hline GN & 29 & 10.34 & 6.90 & 6.90 & 24.14 & 10.34 & 10.34 & 13.79 & 17.24 \\
\hline $\mathrm{HD}$ & 11 & 9.09 & 27.27 & 18.18 & 9.09 & 0.00 & 0.00 & 9.09 & 27.27 \\
\hline $\mathrm{HR}$ & 35 & 2.86 & 17.14 & 17.14 & 11.43 & 11.43 & 8.57 & 14.29 & 17.14 \\
\hline JM & 6 & 50.00 & 16.67 & 16.67 & 16.67 & 0.00 & 0.00 & 0.00 & 0.00 \\
\hline MT & 9 & 33.33 & 0.00 & 22.22 & 0.00 & 11.11 & 0.00 & 0.00 & 33.33 \\
\hline $\mathrm{SH}$ & 41 & 9.76 & 9.76 & 4.88 & 21.95 & 12.20 & 12.20 & 17.07 & 12.20 \\
\hline SD & 9 & 33.33 & 0.00 & 11.11 & 33.33 & 22.22 & 0.00 & 0.00 & 0.00 \\
\hline TC & 34 & 11.76 & 11.76 & 5.88 & 17.65 & 11.76 & 11.76 & 8.82 & 20.59 \\
\hline TN & 23 & 8.70 & 13.04 & 8.70 & 4.35 & 21.74 & 13.04 & 13.04 & 17.39 \\
\hline WG & 13 & 23.08 & 7.69 & 7.69 & 23.08 & 7.69 & 23.08 & 7.69 & 0.00 \\
\hline WL & 12 & 8.33 & 16.67 & 8.33 & 25.00 & 8.33 & 8.33 & 8.33 & 16.67 \\
\hline Total & 384 & 17.13 & 11.30 & 11.27 & 16.80 & 11.60 & 8.72 & 8.24 & 14.92 \\
\hline \multicolumn{10}{|l|}{ (B) DAPC } \\
\hline AR & 51 & & 17.65 & 11.76 & 17.65 & 13.73 & 7.84 & 15.69 & 15.69 \\
\hline $\mathrm{BL}$ & 42 & & 16.67 & 9.52 & 19.05 & 21.43 & 11.90 & 14.29 & 7.14 \\
\hline GG & 22 & & 9.09 & 18.18 & 9.09 & 27.27 & 27.27 & 4.55 & 4.55 \\
\hline GJ & 47 & & 17.02 & 8.51 & 14.89 & 27.66 & 14.89 & 4.26 & 12.77 \\
\hline GN & 29 & & 10.34 & 24.14 & 6.90 & 17.24 & 13.79 & 17.24 & 10.34 \\
\hline $\mathrm{HD}$ & 11 & & 27.27 & 9.09 & 0.00 & 36.36 & 18.18 & 0.00 & 9.09 \\
\hline $\mathrm{HR}$ & 35 & & 20.00 & 20.00 & 5.71 & 22.86 & 14.29 & 5.71 & 11.43 \\
\hline JM & 6 & & 50.00 & 16.67 & 0.00 & 33.33 & 0.00 & 0.00 & 0.00 \\
\hline MT & 9 & & 11.11 & 0.00 & 11.11 & 55.56 & 22.22 & 0.00 & 0.00 \\
\hline $\mathrm{SH}$ & 41 & & 14.63 & 19.51 & 26.83 & 7.32 & 7.32 & 9.76 & 14.63 \\
\hline SD & 9 & & 22.22 & 11.11 & 44.44 & 11.11 & 11.11 & 0.00 & 0.00 \\
\hline TC & 34 & & 23.53 & 11.76 & 8.82 & 11.76 & 20.59 & 17.65 & 5.88 \\
\hline TN & 23 & & 13.04 & 0.00 & 17.39 & 21.74 & 26.09 & 8.70 & 13.04 \\
\hline WG & 13 & & 15.38 & 23.08 & 7.69 & 15.38 & 0.00 & 30.77 & 7.69 \\
\hline WL & 12 & & 16.67 & 25.00 & 25.00 & 8.33 & 16.67 & 0.00 & 8.33 \\
\hline Total & 384 & & 18.89 & 13.89 & 14.31 & 22.07 & 14.14 & 8.57 & 8.04 \\
\hline
\end{tabular}

$\mathrm{AR}=\mathrm{Arsi}, \mathrm{BL}=\mathrm{Bale}, \mathrm{GG}=\mathrm{Gamo}$ Gofa, $\mathrm{GJ}=\mathrm{Gojam}, \mathrm{GN}=$ Gonder, $\mathrm{HD}=$ Hadiya, $\mathrm{HR}=$ Hararghe, JM = Jimma, MT = Metekel, $\mathrm{SH}=\mathrm{Shewa}, \mathrm{SD}=\mathrm{Sidama}, \mathrm{TC}$ $=$ Tigray-Central, $\mathrm{TN}=$ Tigray-Northern, $\mathrm{WG}=$ Wellega, $\mathrm{WL}=$ Wello based on 999 permutations (above diagonal). 


\begin{tabular}{|llllllllllllllll|l|}
\hline & AR & BL & GG & GJ & GN & HD & HR & JM & MT & SH & SD & TC & TN & WG & WL \\
AR & $\mathbf{0 . 0 0 9}$ & 14.456 & 1.905 & 0.918 & 0.892 & 4.136 & 10.167 & 2.177 & 0.354 & 17.607 & 2.726 & 0.236 & 0.337 & 0.396 & 0.437 \\
BL & 0.017 & $\mathbf{0 . 0 0 7}$ & 3.481 & 0.762 & 0.832 & 2.591 & 3.083 & 0.531 & 0.452 & 3.426 & 6.893 & 0.165 & 0.223 & 0.364 & 0.586 \\
\hline GG & 0.116 & 0.067 & $\mathbf{0 . 0 2 7}$ & 0.158 & 0.216 & 7.103 & 0.479 & 1.810 & 9.778 & 3.987 & 6.329 & 0.342 & 0.249 & 2.044 & 0.364 \\
\hline GJ & 0.214 & 0.247 & $\mathbf{0 . 6 1 2}$ & $\mathbf{0 . 0 0 9}$ & 11.114 & 0.559 & 0.375 & 0.897 & 3.538 & 8.371 & 0.364 & 0.988 & 1.703 & 1.013 & 7.815 \\
\hline GN & 0.219 & 0.231 & 0.536 & 0.022 & $\mathbf{0 . 0 0 8}$ & 0.373 & 0.559 & 5.185 & 6.507 & 5.432 & 0.964 & 4.380 & 6.160 & 1.229 & 10.620 \\
\hline HD & 0.057 & 0.088 & 0.034 & 0.309 & 0.401 & $\mathbf{0 . 0 1 7}$ & 0.886 & 4.214 & 11.655 & 7.326 & 2.559 & 0.370 & 0.158 & 9.009 & 0.357 \\
\hline HR & 0.024 & 0.075 & 0.343 & 0.400 & 0.309 & 0.220 & $\mathbf{0 . 0 0 8}$ & 1.073 & 0.539 & 4.136 & 0.572 & 0.222 & 0.234 & 1.080 & 2.955 \\
\hline JM & 0.103 & 0.320 & 0.121 & 0.218 & 0.046 & 0.056 & 0.189 & 0.037 & 7.326 & 4.380 & 0.994 & 0.237 & 0.302 & 14.456 & 0.586 \\
\hline MT & 0.414 & 0.356 & 0.025 & 0.066 & 0.037 & 0.021 & 0.317 & 0.033 & $\mathbf{0 . 0 1 4}$ & 3.917 & 1.116 & 0.227 & 0.460 & 7.815 & 1.462 \\
\hline SH & 0.014 & 0.068 & 0.059 & 0.029 & 0.044 & 0.033 & 0.057 & 0.054 & 0.060 & $\mathbf{0 . 0 1 0}$ & 7.326 & 2.624 & 3.718 & 5.306 & 9.365 \\
\hline SD & 0.084 & 0.035 & 0.038 & 0.407 & 0.206 & 0.089 & 0.304 & 0.201 & 0.183 & 0.033 & $\mathbf{0 . 0 0 8}$ & 0.373 & 0.239 & 1.256 & 0.370 \\
TC & 0.514 & 0.603 & 0.422 & 0.202 & 0.054 & 0.403 & 0.530 & 0.513 & 0.524 & 0.087 & 0.401 & $\mathbf{0 . 0 1 1}$ & 20.583 & 1.087 & 18.981 \\
\hline TN & 0.426 & 0.529 & 0.501 & 0.128 & 0.039 & $\mathbf{0 . 6 1 2}$ & 0.516 & 0.453 & 0.352 & 0.063 & 0.511 & $\mathbf{0 . 0 1 2}$ & $\mathbf{0 . 0 1 1}$ & 1.179 & 4.214 \\
\hline WG & 0.387 & 0.407 & 0.109 & 0.198 & 0.169 & 0.027 & 0.188 & 0.017 & 0.031 & 0.045 & 0.166 & 0.187 & 0.175 & $\mathbf{0 . 0 0 7}$ & 2.799 \\
\hline WL & 0.364 & 0.299 & 0.407 & 0.031 & 0.023 & 0.412 & 0.078 & 0.299 & 0.146 & 0.026 & 0.403 & $\mathbf{0 . 0 1 2}$ & 0.056 & 0.082 & $\mathbf{0 . 0 0 6}$ \\
\hline
\end{tabular}

$\mathrm{AR}=\mathrm{Arsi}, \mathrm{BL}=$ Bale, $\mathrm{GG}=$ Gamo Gofa, GJ = Gojam, $\mathrm{GN}=$ Gonder, $\mathrm{HD}=$ Hadiya, $\mathrm{HR}=$ Hararghe, $\mathrm{JM}=\mathrm{Jimma}, \mathrm{MT}=\mathrm{Metekel}, \mathrm{SH}=\mathrm{Shewa}, \mathrm{SD}=\mathrm{Sidama}, \mathrm{TC}$ $=$ Tigray-Central, $\mathrm{TN}=$ Tigray-Northern, $\mathrm{WG}=$ Wellega, $\mathrm{WL}=$ Wello

Table 6. Genetic distance among the barley populations

\begin{tabular}{|c|c|c|c|c|c|c|c|c|c|c|c|c|c|c|c|}
\hline & AR & $\mathrm{BL}$ & GG & GJ & $\mathrm{GN}$ & $\mathrm{HD}$ & $\mathrm{HR}$ & $\mathrm{JM}$ & MT & $\mathrm{SH}$ & SD & $\mathrm{TC}$ & $\mathrm{TN}$ & WG & WL \\
\hline AR & - & & & & & & & & & & & & & & \\
\hline$B L$ & 0.017 & - & & & & & & & & & & & & & \\
\hline GG & 0.132 & 0.230 & - & & & & & & & & & & & & \\
\hline GJ & 0.214 & 0.314 & 0.324 & - & & & & & & & & & & & \\
\hline $\mathrm{GN}$ & 0.224 & 0.320 & 0.332 & 0.020 & - & & & & & & & & & & \\
\hline$H D$ & 0.136 & 0.140 & 0.035 & 0.327 & 0.337 & - & & & & & & & & & \\
\hline HR & 0.032 & 0.131 & 0.132 & 0.222 & 0.320 & 0.218 & - & & & & & & & & \\
\hline JM & 0.174 & 0.268 & 0.167 & 0.267 & 0.366 & 0.287 & 0.265 & - & & & & & & & \\
\hline MT & 0.258 & 0.343 & 0.150 & 0.229 & 0.260 & 0.141 & 0.254 & 0.093 & - & & & & & & \\
\hline $\mathrm{SH}$ & 0.024 & 0.122 & 0.141 & 0.024 & 0.123 & 0.049 & 0.030 & 0.077 & 0.271 & - & & & & & \\
\hline SD & 0.132 & 0.030 & 0.057 & 0.344 & 0.447 & 0.070 & 0.261 & 0.140 & 0.283 & 0.141 & - & & & & \\
\hline $\mathrm{TC}$ & 0.417 & 0.428 & 0.434 & 0.315 & 0.423 & 0.433 & 0.428 & 0.468 & 0.443 & 0.331 & 0.549 & - & & & \\
\hline $\mathrm{TN}$ & 0.417 & 0.524 & 0.532 & 0.416 & 0.429 & 0.433 & 0.424 & 0.471 & 0.535 & 0.430 & 0.541 & 0.018 & - & & \\
\hline WG & 0.232 & 0.032 & 0.245 & 0.329 & 0.435 & 0.253 & 0.344 & 0.391 & 0.055 & 0.331 & 0.454 & 0.330 & 0.339 & - & \\
\hline WL & 0.340 & 0.047 & 0.339 & 0.035 & 0.037 & 0.362 & 0.149 & 0.392 & 0.375 & 0.038 & 0.457 & 0.045 & 0.088 & 0.345 & - \\
\hline
\end{tabular}

$\mathrm{AR}=\mathrm{Arsi}, \mathrm{BL}=$ Bale, GG = Gamo Gofa, GJ = Gojam, GN = Gonder, HD = Hadiya, HR = Hararghe, JM = Jimma, MT = Metekel, SH = Shewa, SD = Sidama, $\mathrm{TC}$

$=$ Tigray-Central, $\mathrm{TN}=$ Tigray-Northern, $\mathrm{WG}=$ Wellega, $\mathrm{WL}=$ Wello

Table 7. Analysis of molecular variance (AMOVA) among and within barley subpopulations.

Page 18/23 


\begin{tabular}{|lccccllll|}
\hline Source & df & SS & MS & Est. Var. & $\%$ & F ST & Nm \\
\hline Based on Zones of origin & & & & & & \\
\hline Among Population & 14 & 154.387 & 11.028 & 0.029 & $15.79 \%$ & $0.053^{\star *}$ & 4.467 \\
\hline Within Population & 369 & 3800.334 & 10.299 & 10.299 & $84.21 \%$ & & \\
\hline Total & 383 & 3954.721 & & 10.328 & $100 \%$ & & \\
\hline Based on Breeding Status & & & & & & \\
Among Population & 1 & 27.511 & 27.511 & 1.100 & $10.57 \%$ & $0.097^{\star *}$ & 2.327 \\
\hline Within Population & 382 & 3927.210 & 10.281 & 10.281 & $89.49 \%$ & & \\
\hline Total & 383 & 3954.721 & & 11.380 & $100 \%$ & & \\
\hline Based on Kernel Row Number & & & & & & \\
\hline Among Population & 2 & 67.245 & 33.622 & 0.223 & $3.95 \%$ & $0.221^{\star *}$ & 0.881 \\
\hline Within Population & 381 & 3887.477 & 10.203 & 10.203 & $96.05 \%$ & & \\
\hline Total & 383 & 3954.721 & & 10.426 & $100 \%$ & & \\
\hline
\end{tabular}

$\mathrm{df}=$ Degree of freedom, $\mathrm{SS}=$ Sum of squares, MS = Mean square, Est. Var. = estimated variance,

$\%=$ percent variance, $\mathrm{F}_{\mathrm{ST}}=$ genetic differentiation, $\mathrm{Nm}=$ estimates of gene flow

\section{Figures}

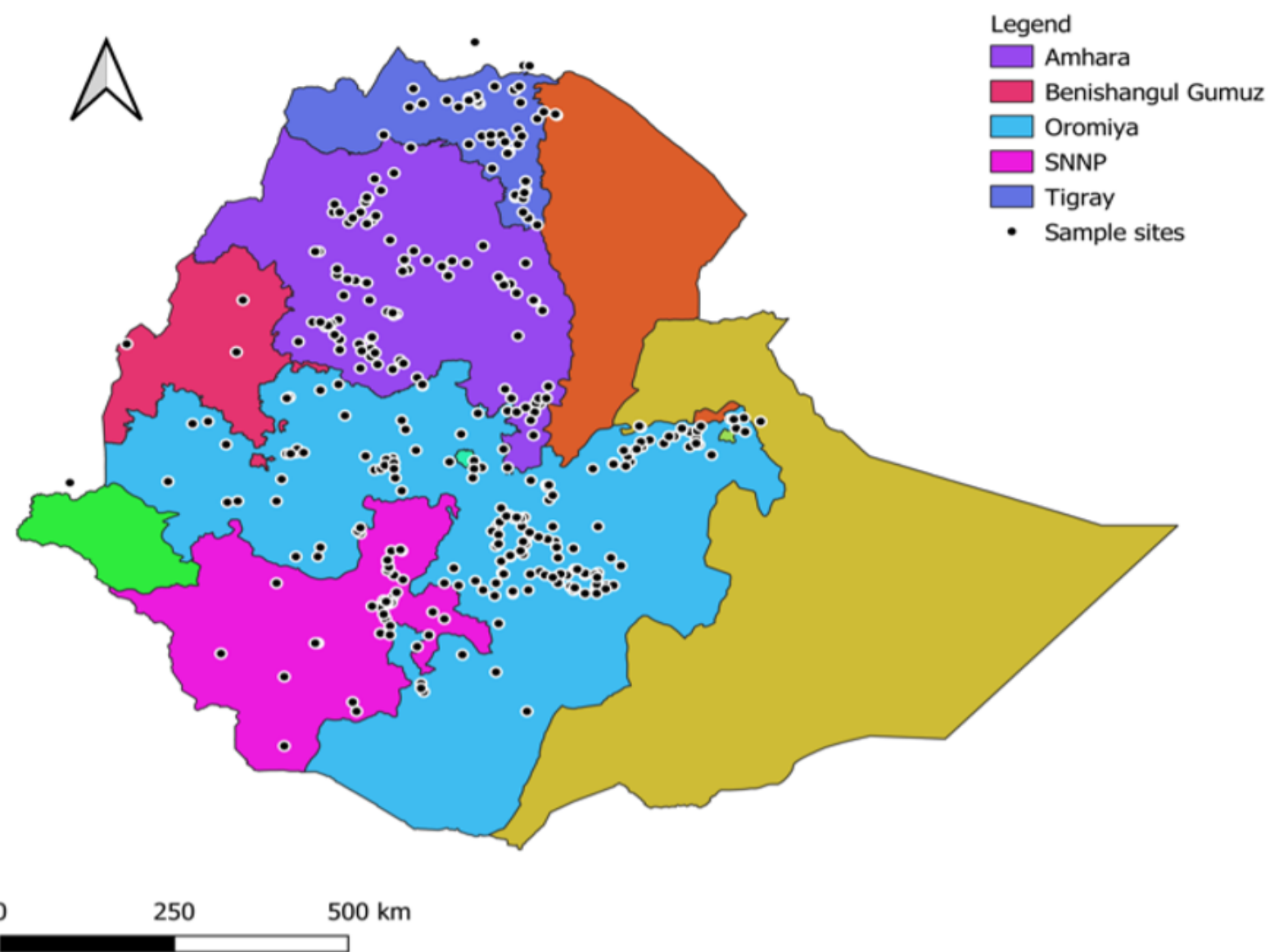


Map of Ethiopia showing the collection sites of barley landraces based on Ethiopian National Regional States. The map was constructed using the QGISOSGeo4W Version 3.8.0 software.

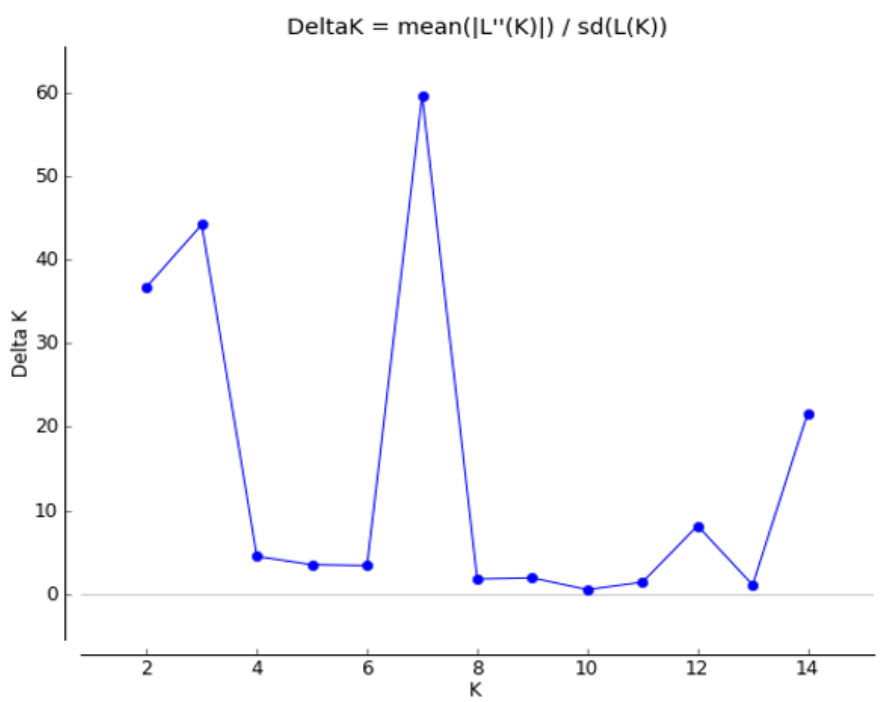

(A)

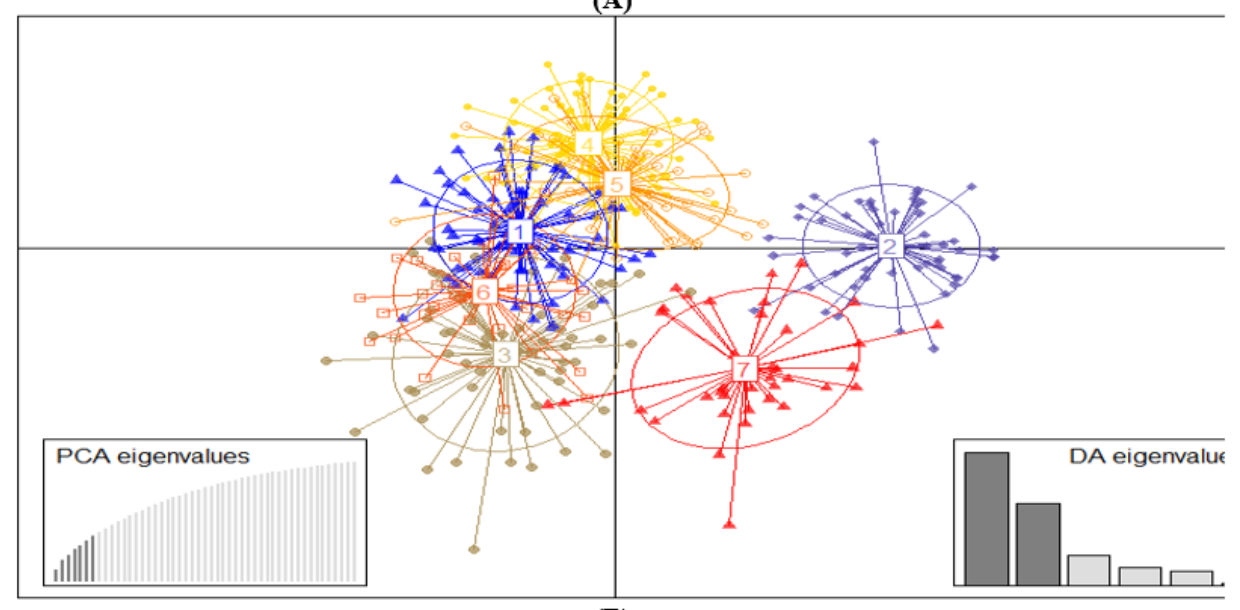

(B)

Figure 2

(A) $\triangle \mathrm{K}$ plot showing its maximum value at $\mathrm{K}=7$ suggesting the optimal number of genetic clusters of seven, (B) Scattered plot of DAPC, each color represents one cluster and 


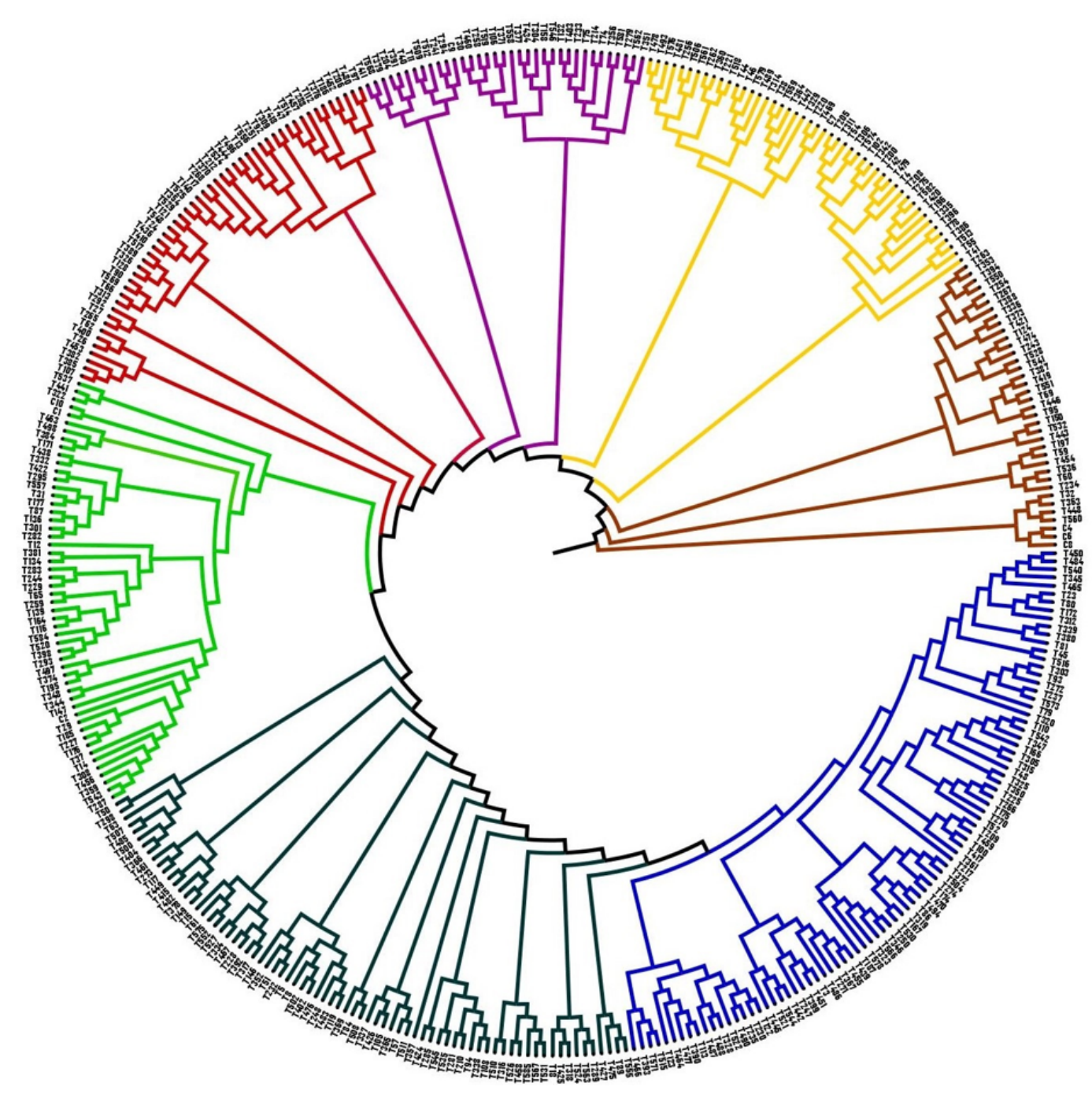

Figure 3

UPGMA dendrogram showing the genetic relationships among 384 barley accessions grouped into seven distinct clusters generated based on loci with a minor allele frequency of 0.3 , using evolutionary distances computed by the Nei 1983 method. The accessions were coded in such a way that the first letter stands for treatment and the number is order of treatment in ascending order of accession code. The seven colors represent the seven clusters and the proportion of each color in each accession represents the average proportion of the alleles that placed each accession under the seven clusters, Cluster 1 = Light Blue, cluster 2 = Dark Blue, cluster 3 = Brown, cluster 4 = Orange, cluster $5=$ Yellow, cluster $6=$ Purple and cluster $7=$ Red) . 
A
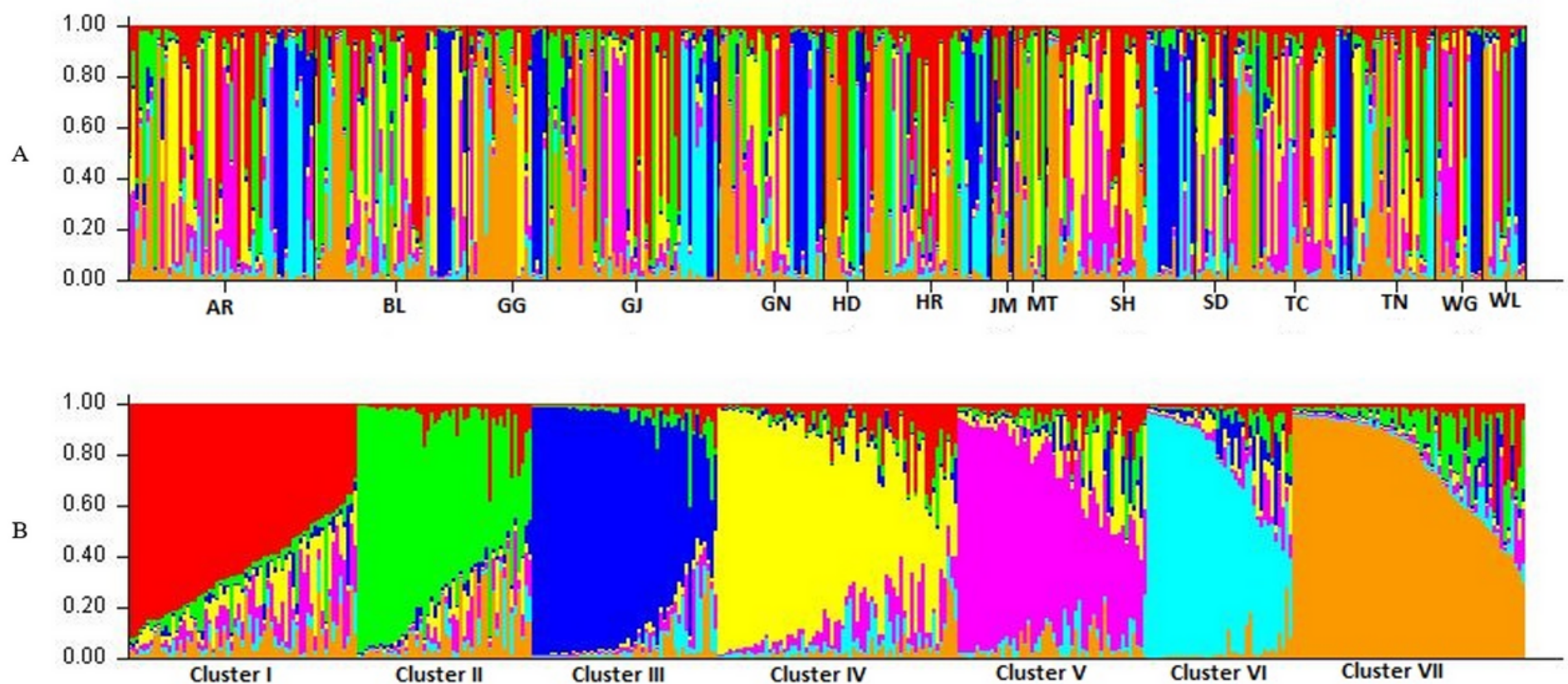

Figure 4

Population structure of 384 barley individuals based on 49 SSR markers. At $K=7$, the 384 individuals were classified into seven groups by STRUCTURE analysis. (A) Ordered by geographic population. (B) Ordered by admixture proportion. The seven colors represent the seven clusters and the proportion of each color in each accession represents the average proportion of the alleles that placed each accession under the seven clusters, $\mathrm{AR}=\mathrm{Arsi}, \mathrm{BL}=\mathrm{Bale}, \mathrm{GG}$ = Gamo Gofa, GJ = Gojam, GN = Gonder, HD = Hadiya, HR = Hararghe, JM = Jimma, MT = Metekel, SH = Shewa, SD = Sidama, $\mathrm{TC}=\mathrm{Tigray}-\mathrm{Central}, \mathrm{TN}=$ Tigray-Northern, $\mathrm{WG}=$ Wellega, $\mathrm{WL}=$ Wello . 


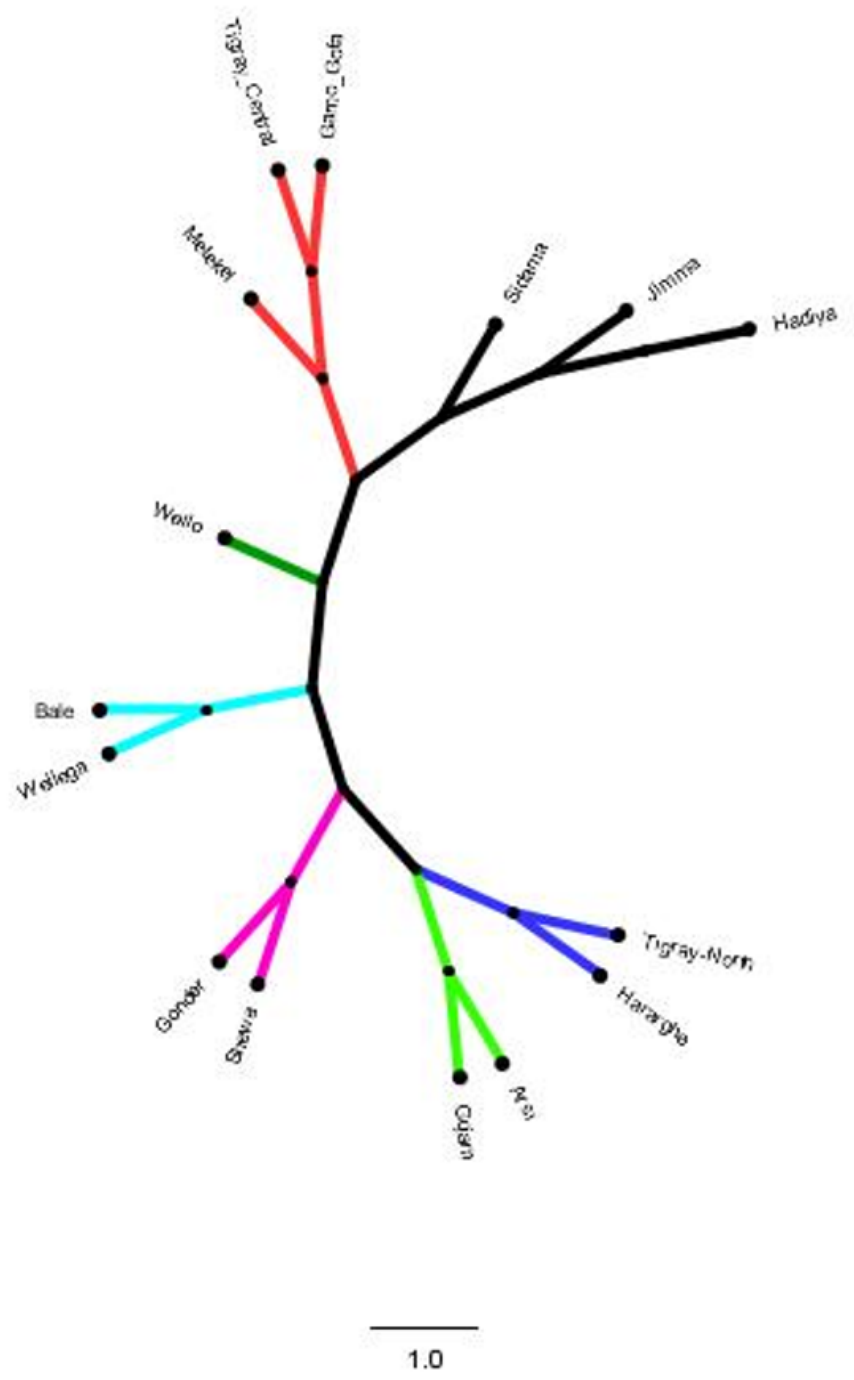

Figure 5

Phylogenetic tree among 15 barley collection Zones based on the genetic-distance matrix using the neighbor-joining method by PowerMarker version3.25 and visualized using the software MEGA X. and Fig Tree. 